This is the author's final, peer-reviewed manuscript as accepted for publication. The publisher-formatted version may be available through the publisher's web site or your institution's library.

\title{
Implementing COOL: comparative welfare effects of different labeling schemes
}

Siny Joseph, Nathalie Lavoie, Julie A. Caswell

\section{How to cite this manuscript}

If you make reference to this version of the manuscript, use the following information:

Joseph, S., Lavoie, N., \& Caswell, J. A. (2014). Implementing COOL: Comparative welfare effects of different labeling schemes. Retrieved from http://krex.ksu.edu

\section{Published Version Information}

Citation: Joseph, S., Lavoie, N., \& Caswell, J. A. (2014). Implementing COOL: Comparative welfare effects of different labeling schemes. Food Policy, 44, 14-25.

Copyright: ( 2013 Elsevier Ltd.

Digital Object Identifier (DOI): doi:10.1016/j.foodpol.2013.10.008

Publisher's Link: http://www.sciencedirect.com/science/article/pii/S0306919213001565

This item was retrieved from the K-State Research Exchange (K-REx), the institutional repository of Kansas State University. K-REx is available at http://krex.ksu.edu 


\title{
Implementing COOL:
}

\section{Comparative Welfare Effects of Different Labeling Schemes}

\author{
Siny Joseph \\ Assistant Professor, Department of Arts, Sciences, and Business \\ Kansas State University Salina \\ 2310 Centennial Road, Salina, KS 67401-8196 \\ siny@k-state.edu \\ Nathalie Lavoie \\ Associate Professor, Department of Resource Economics \\ University of Massachusetts Amherst \\ 80 Campus Center Way, Amherst, MA, 01003 \\ lavoie@resecon.umass.edu \\ Julie A Caswell \\ Professor, Department of Resource Economics \\ University of Massachusetts Amherst \\ 80 Campus Center Way, Amherst, MA, 01003 \\ caswell@resecon.umass.edu
}




\section{Abstract}

Country-of-Origin Labeling (COOL) is being implemented in different forms and degrees in the United States and other countries across the world. The first implementation of Mandatory Country of Origin Labeling (MCOOL) in the United States was for seafood in 2005. This is an example of partial MCOOL because it exempts the foodservice sector and excludes processed seafood from labeling. Using a conceptual framework, we analyze the welfare impacts of partial MCOOL when compared to no, voluntary, and total mandatory COOL, taking into account imperfect competition in the downstream markets, information asymmetry, and diversion of lowquality product to the unlabeled market. The model is general enough to apply to any incomplete regulation for which the perceived low-quality product is required to be labeled, such as the labeling of genetically modified food in the European Union. Our results show that when consumers have a strong enough preference for domestic relative to imported product, regulators can overestimate the gain in consumer welfare from partial mandatory labeling if they ignore the diversion of lower quality imports to the unlabeled sector. We show that if the preference for domestic product is large enough, total MCOOL benefits the home market the most overall, including domestic consumers and producers, but not the imperfectly competitive downstream agents. However, if total MCOOL is too costly to implement, partial MCOOL is the second-best solution, but only if consumers falsely believe the unlabeled product to be of higher quality than it truly is. Our results suggest more research is needed to determine the extent to which consumers value the information provided by MCOOL and to enable regulators to consider the welfare impact of diversion in evaluating incomplete mandatory labeling regulations.

Keywords: Country of origin labeling, product differentiation, information asymmetry, food quality, incomplete regulation. 


\section{Introduction}

Incidents with the safety of imports as well as consumer interest in domestically produced products generate support for mandatory country-of-origin labeling (MCOOL) for foods. For example, prominent safety incidents in the United States include recalls of a number of Chinesemade products including farm-raised shrimp, catfish, pet food, and toothpaste. At the same time, a food labeling poll conducted by Consumer Reports 2007 shows that consumers want to know where their food comes from and expect higher label standards. According to the poll, $92 \%$ of United States consumers agree that imported foods should be labeled by country of origin. Proponents of MCOOL in the United States believe labels cater to the consumer's right to know about the origins of food products. Opponents believe the labeling law is a protectionist measure, aided by false perceptions about the quality of imported products. They consider the labeling process to be expensive and cumbersome.

Our analysis is motivated by the adoption of different forms and degrees of implementation of MCOOL for particular products. For example, the first implementation of MCOOL in the United States was for fish and shellfish in 2005. It is part of a broader program to label fresh meats, vegetables, fruits, and other fresh foods. The stated objective was to communicate to consumers the national origin and method of production (wild or farm-raised) of seafood via mandatory labels. However, the labels are restricted to fresh and frozen seafood at the retail level. Foodservice establishments, small retailers, and processed seafood products are exempt. As such, we call this current implementation of the law "partial MCOOL."

Demand for fish and seafood has grown rapidly in the United States (National Marine Fisheries Service, 2011). U.S. consumers spent an estimated $\$ 75.5$ billion for fishery products in 
2009 , including $\$ 50.3$ billion at restaurants, carry-outs, and caterers and $\$ 23.8$ billion in retail sales for consumption at home. Currently, over $84 \%$ of the seafood Americans consume is imported (National Marine Fisheries Service, 2011). The overall exempt market (foodservice establishments, retailers not subject to the rule, and processed products) under partial MCOOL accounts for $62 \%$ of fish and $75 \%$ of shellfish (USDA-AMS, 2004). Thus most of the foreign seafood consumed in United States is not labeled under partial MCOOL.

This partial implementation of MCOOL raises opportunities for product diversion into unlabeled markets. According to the U.S. Department of Commerce, over $80 \%$ of the total imported edible seafood in 2009 came from less developed countries. In the United States, the use of the Hazard Analysis Critical Control Points (HACCP) system is required to ensure the safety of seafood. While imports are required to meet the same HACCP standards, enforcement may be weaker and a small fraction of imported product is inspected by the FDA (Racino, 2011). Countries also vary in their use of vaccines, feed additives, and antibiotics for farm-raised fish and shellfish (Allshouse et al., 2004). The U.S. Center for Disease Control (CDC) and Prevention reported in 2012 that foodborne illness outbreaks due to imported food products had risen between 2009 and 2010, with fish as the most common culprit and Asia as the most common source (CDC, 2012). The partial MCOOL regulation specifically states that labeling is not a sanitary (food safety) measure - safety assurance is accomplished through other regulatory programs. However, diversion may occur when imported products, particularly those from less developed countries (Verlegh and Steenkamp, 1999), may be perceived by consumers to be of lower quality.

While the seafood industry motivates our study, our model is general enough to apply to other cases where products perceived to be of low quality are required to be labeled and labeling 
is implemented in a partial fashion. ${ }^{1}$ A non-MCOOL example of partial regulation is the labeling of GM food where processed products are often excluded from mandatory labeling (Gruère and Rao, 2007). ${ }^{2}$ This study contributes to the literature on the impact of country-of-origin labeling, and partial labeling regulations in general, by focusing specifically on the possibility of diversion of perceived low-quality imported products to the unlabeled market, while considering the market power of sellers and their ability to benefit from the asymmetry of information.

\section{Modeling the Implementation of Different Forms of COOL}

Most of the literature on the effects of MCOOL models the total implementation of MCOOL (thereinafter "total MCOOL"), i.e., the models do not take into account the exempted sectors and products excluded from the labeling law. Exceptions include articles using the computable general equilibrium (CGE) model of the Economic Research Service (ERS), which makes use of cost of implementation estimates of the USDA-AMS, i.e., Krissoff et al. (2004) and Jones, Somwaru and Whitaker (2009). The Federal Register (2004 and 2009) details how those costs are estimated for fish and shellfish and other covered commodities and how values are adjusted (or not) to account for exempted establishments and excluded products. The increase in cost associated with the law is used within the CGE model to determine the resulting change in production and consumption. The model assumes that retailers are perfectly competitive and that COOL does not result in increased consumer demand for domestic products.

\footnotetext{
${ }^{1}$ Other covered commodities under MCOOL include muscle cuts of beef (including veal), lamb, chicken, goat, and pork; ground beef, ground lamb, ground chicken, ground goat, and ground pork; perishable agricultural commodities; macadamia nuts; pecans; ginseng; and peanuts. As with fish and shellfish, food service establishments are exempted from the law, and commodities that are processed or an ingredient in a processed food item are excluded from labeling (Federal Register, 2009).

${ }^{2}$ In many industrialized countries, GM food is less desirable than non-GM food.
} 
Most other studies have focused on estimating the welfare effects of total MCOOL. ${ }^{3}$ Lusk and Anderson (2004); Brester, Marsh and Atwood (2004) and Chung, Zhang, and Peel (2009) examine the welfare effects on the meat/livestock industry. The result of those studies is that producer losses due to the cost of implementation can be offset if there is a sufficient increase in demand, i.e., in the range of 2 to 4.4 percent depending on the study and assumptions used in the equilibrium displacement model. Saak (2011) demonstrates that total MCOOL decreases welfare when relative input costs are volatile and varieties are similar in overall quality. He also finds that total MCOOL may not only reduce the size of the market, but also worsen the distortion in the allocation of the market shares across varieties. Cheaper variety tends to be oversupplied under voluntary COOL but undersupplied under total MCOOL. Johnecheck, Wilde, and Caswell (2010) simulate the ex-ante market and welfare outcomes of MCOOL adoption in the U.S. on the U.S.-Mexican tomato trade. Their results show that in all scenarios where consumers show a relative preference for U.S. tomatoes, consumer level impacts are small while the producer impact is large, with transfer from Mexican to U.S. producers. Plastina, Giannakas, and Pick (2011) examine welfare effects of total MCOOL in the U.S. specialty crop sector. The model developed accounts for imperfect competition among retailers and considers consumer and producer heterogeneity in determining the welfare effects on supply chain participants. Their simulation results for the U.S. apple industry show that consumers and producers are more likely to gain from total MCOOL under low labeling costs and/or a strong consumer preference for domestic apples.

\footnotetext{
${ }^{3}$ We conclude that the studies examine total MCOOL as opposed to partial MCOOL because of the use of aggregated data and because there is no mention that the model is adjusted for exempted sectors and excluded products.
} 
Kuchler, Krissoff and Harvey (2010) exploit the partial implementation of MCOOL to examine its effect on shrimp consumption. They consider three types of shrimp products: random-weight, frozen bagged, and frozen bagged and breaded shrimp. They hypothesize that MCOOL should have the greatest effect on the consumption of random-weight shrimp (MCOOL requires country of origin and wild/farm indicator), and the least effect on frozen bagged and breaded shrimp (excluded from labeling under the law). ${ }^{4}$ Using weekly Nielsen Homescan panel data from 1998 to 2006, they find no significant effect of MCOOL on consumption.

Consumer preference for domestic products is an important criterion to analyze benefits of mandatory COOL implementation. A number of studies have illustrated that U.S. consumers are willing to pay a premium for U.S.-origin labeled beef and pork products over products from other countries (e.g., Umberger et al. 2003; Ward et al. 2005; Miranda and Kónya 2006; Loureiro and Umberger 2007; Mennecke et al. 2007; Gao and Schroeder 2009; Link 2009). Using an analytical framework, Awada and Yiannaka (2012) show that whether consumers view total MCOOL information as an attribute that differentiates product vertically or horizontally does not alter the consumer welfare effects of total MCOOL. Rather they show that it is the strength of consumer preferences that affects magnitude of market and welfare effects of COOL. Klain et. al. (2011) show that while willingness-to-pay (WTP) for U.S. over foreign meat is relevant to the debate on MCOOL, it is not what is needed in a cost-benefit analysis of MCOOL. Rather, analysts need to know the value of information related to product origin. According to their study approximately $82 \%$ of the subjects in the study were not aware of MCOOL and $60 \%$ claimed to never have looked for origin labels when purchasing meat.

\footnotetext{
${ }^{4}$ Frozen bagged shrimp is less affected by MCOOL then random-weight shrimp because under the Tariff Act of 1930 origin labels were already required on consumer-ready packages such as bagged shrimp. However, MCOOL require the addition of the wild/farm indicator.
} 
No one to date has studied the economic impacts of an incomplete labeling regulation, such as the partial implementation of MCOOL relative to total MCOOL. However, the possible diversion of imported products to unlabeled markets has been noted (Iqbal, Kim, and Rude 2006; USDA-AMS 2004; Hammonds 2003).

The model developed here contributes a distinct focus on the economic impacts of partial implementation of MCOOL on consumers, sellers, and total welfare. The model accounts for imperfect competition downstream, consumer heterogeneity in terms of preference for domestic relative to foreign products, and information asymmetry when the product is unlabeled. Further, we allow diversion of foreign product into the unlabeled (e.g., food service) sector under partial MCOOL by modeling the behavior of the retailer and food service sectors separately.

To analyze the impact of various forms and degrees of implementation of country-oforigin labeling, we consider welfare under four alternate scenarios: no COOL, voluntary COOL, partial MCOOL, and total MCOOL. The first two pre-COOL scenarios (no COOL and voluntary COOL) are benchmark scenarios against which two alternative implementations of mandatory COOL (partial and total) are compared. Awada and Yiannaka (2012) show that the benchmark used (a no COOL versus a voluntary COOL regime) is critical in evaluating the effects of the policy. Under no COOL the origin of the product cannot be distinguished by consumers. Consequently, there is imperfect and asymmetric information. While consumers are unable to differentiate domestic product from foreign, we assume that sellers in retail and foodservice sectors can differentiate them. The voluntary labeling scenario allows us to explore under what circumstances retailers would choose to voluntarily label the domestic product.

We represent the current U.S. partial MCOOL implementation by having the high- and low-quality products labeled in the retail sector only. In contrast, high- and low-quality products 
are labeled in both retail and foodservice sectors under total MCOOL. The different cases are shown schematically in figure 1.

We model a good that is vertically differentiated according to country of origin. There are two countries, i.e., the home country (e.g., the United States) and a foreign country that is a representative major exporter of the product to the home country. We assume that domestic firms produce the high-quality good $\left(k_{H}\right)$ and foreign firms produce products of lower quality $\left(k_{L}\right)$ or are at least perceived as such. Consistent with previous models of labeling (e.g., Bureau, Marette and Schiavina, 1998; Giannakas and Fulton, 2002; Fulton and Giannakas, 2004; Zago and Pick, 2004; Plastina, Giannakas, and Pick, 2011, Saak, 2011, Awada and Yiannaka, 2012), we assume that quality is fixed and exogenous. Furthermore, it is the quality perceived by consumers that is represented by $k$ in our model. Lusk and Marette (2012) model perceived quality as a function of the objective quality level and the consumer's level of attention, all exogenous variables. Quality perception is formed over time from a variety of intrinsic and extrinsic cues received by consumers. It is beyond the scope of this article to model the source of consumers' perceptions. ${ }^{5}$

Our model builds on those developed by Bureau, Marette and Schiavina (1998), Zago and Pick (2004), and Plastina, Giannakas, and Pick (2011). Unlike the first two articles, we model intermediaries with market power. This feature is important because whenever there is labeling (i.e., voluntary $\mathrm{COOL}$, partial $\mathrm{MCOOL}$, or total MCOOL), there is perceived quality differentiation. Labeling offers sellers the opportunity to exercise second-degree price discrimination, where consumers self-select into groups, i.e., two price-quality bundles. In addition, the presence of an unlabeled market segment (i.e., under no COOL, voluntary COOL,

\footnotetext{
${ }^{5}$ According to Lusk et al. (2006), consumer ethnocentrism - a term that refers to consumption patterns reflecting the feeling of national superiority - is another reason why consumers may have a higher preference or willingness to pay for domestic products.
} 
or partial MCOOL) opens the possibility for the seller to benefit from consumers' lack of information about the product. An unlabeled segment causes distortion in the market, and the labeling of low-quality product in only some market segments causes diversion. Thus different forms of labeling can benefit sellers and affect consumer and total welfare to different degrees. Unlike Plastina, Giannakas and Pick (2011), consumers in our model interact in two markets: retail and foodservice. This feature, along with two pre-MCOOL scenarios (no COOL and voluntary COOL) and two post-MCOOL scenarios (partial and total MCOOL), allows us to examine the welfare effects of diversion of low-quality product to unlabeled market segments.

\section{Supply side}

The product supply chain is characterized by farmers (harvesters/producers), intermediaries (processors, importers, wholesalers and handlers), and retailers/foodservice establishments. For simplicity we consider two levels: firms and establishments; where firms include farmers and intermediaries, and establishments are defined as retail/foodservice establishments. Firms are further classified as foreign and domestic based on the origin of the product supplied. In this model, domestic and foreign firms are assumed to be perfectly competitive. In light of the rise in concentration in grocery retailing and following previous literature (e.g., Plastina, Giannakas, and Pick, 2011), we assume that establishments (retail and foodservice) have market power. ${ }^{6}$

We model the pre-MCOOL scenarios (no and voluntary COOL) as part of a three-stage game, where in stage 1 retailers choose whether to label the high-quality product, in stage 2 , upstream supply is equated with demand to determine the price to downstream markets, and in

\footnotetext{
${ }^{6}$ According to U.S. Census Bureau data, the four-firm concentration ratio for supermarkets and other grocery (except convenience) stores (NAICS 44511) has risen from 20.8 percent in 1997 to 32 percent in 2007 . The rise in concentration at the national level is likely linked to a rise in concentration at the local level.
} 
stage 3, all downstream agents (retailers and foodservice firms) set quantity to maximize profits. MCOOL is by definition mandatory and the first stage is omitted in post-COOL scenarios.

Let each firm $j$ (supplier to retail/foodservice) maximize profit $\pi_{i j}$, and produce a quantity $q_{i j} \in \Re_{+}$of the type $i=L, H$ where $i$ represents quality and $j=1$ to $N$. The aggregate supply $q_{i}=Q_{i}\left(w_{i}\right)$ is the summation of individual supply $q_{i j}$ for each quality $i$ and $w_{i}$ is the market price to the retail or foodservice sector. The overall firms' surplus, $\Pi_{i}$, is the sum of individual profits $\pi_{i j}$. To keep the expressions as simple as possible, we follow Bureau, Marette, and Schiavina (1998) and Zago and Pick (2004) and express the surplus for firms of quality $i$ as:

$$
\pi_{i j}=q_{i j} w_{i}-0.5 c_{i} n_{i}\left(q_{i j}\right)^{2}
$$

where $n_{i}$ is the number of firms of quality $i$. The cost function is quadratic and there is decreasing returns to scale. Note also that this specification implies that domestic and foreign firms produce with different technologies and costs of production. Parameters $c_{L}$ and $c_{H}$ reflect production costs for the two qualities such that $c_{L}<c_{H}$. That is, foreign product can be produced and sold at a lower price than domestic product. The first-order conditions with respect to $q_{i j}$ imply that $w_{i}$ $c_{i} n_{i} q_{i j}=0$. Thus, the aggregate supply of quality $i$ is expressed as:

$$
Q_{i}\left(w_{i}\right)=w_{i} / c_{i}
$$

Labeling generates segregation, identity preservation, and labeling costs. In our model, we account only for additional labeling costs generated by MCOOL. Under the Tariff Act of 1930, which is still in force, exporters are required to inform the country of origin with labels to the "ultimate purchaser," irrespective of MCOOL implementation. Ultimate purchaser is defined as the last U.S. person who receives the product in the form in which it was imported. For 
example, if foreign firms export seafood in retail-ready packages (e.g., bag of frozen shrimps), the package is already labeled with country of origin by the Tariff Act of $1930 .^{7}$ In the case of seafood exported in bulk containers and sold fresh or frozen at the retailer's seafood counter, it is the container that has origin information under the Tariff Act of 1930. In this case, prior to MCOOL the retailer was not required to label the product by country of origin.

With MCOOL and voluntary COOL, systems must be implemented to ensure that the origin and production information of domestic product is transferred from producers to the next buyers, and the information is maintained for the required amount of time. In our model, only domestic firms bear the operating costs $y$ (segregation and identity preservation). MCOOL and voluntary COOL do not generate additional costs for foreign firms. If the final-consumer product is not already labeled by the Tariff Act of 1930, MCOOL and voluntary COOL generate additional labeling costs $b$ to retailers. To keep our model general, we assume that MCOOL and voluntary COOL generate an additional labeling cost for all product labeled at retail.

\section{Demand side}

In our model of heterogeneous consumers, the characterization of consumer preferences follows the model of vertical product differentiation by Mussa and Rosen (1978), which accounts for differences in consumer attitudes toward product quality. The continuum of consumers, indexed by their preference $\theta$ (or willingness to pay) for product quality, is uniformly distributed over $[0, \bar{\theta}]$ with density $1 / \bar{\theta}$. Each consumer buys at most one unit and the associated utility is $U=\theta k-p$, where $p$ is the price of the good of quality $k$. The market is not entirely covered and consumers who buy nothing have a utility of zero.

\footnotetext{
${ }^{7}$ In the case of seafood, the Tariff Act of 1930 does not require the labels to indicate the method of production, i.e., farmed or wild caught. MCOOL adds the requirement that they also be labeled farmed or wild caught.
} 
The consumer indifferent between buying a product of quality $k$ and buying nothing is the consumer with value of $\theta$ such that $\theta k-p=0$, i.e., $\theta=p / k$. Thus, consumers with $\theta \in[0 ; p / k)$ buy nothing, and consumers with $\theta \in[p / k ; \bar{\theta}]$ buy one unit. Accordingly, the demand for the product is the length of the consumer interval buying the product multiplied by the density of consumers times the total number of consumers, $N=1$, i.e., $\frac{1}{\bar{\theta}}\left(\bar{\theta}-\frac{p}{k}\right)$.

With two products of quality $k_{1}$ and $k_{2}$, where $k_{1}>k_{2}$, there are two indifferent consumers: the consumer indifferent between buying nothing and buying the product of quality $k_{2}$, and the consumer indifferent between buying the product of quality $k_{2}$ and the product of quality $k_{1}$. The indifferent consumers are respectively $\theta_{2}=p_{2} / k_{2}$ and $\theta_{1}=\left(p_{1}-p_{2}\right) /\left(k_{1}-k_{2}\right)$, where $p_{i}$ is the price of quality $i$, and $p_{1}>p_{2}$. The demands for each quality are $D_{2}=\frac{1}{\bar{\theta}}\left(\frac{p_{1}-p_{2}}{k_{1}-k_{2}}-\frac{p_{2}}{k_{2}}\right)$ and $D_{1}=\frac{1}{\bar{\theta}}\left(\bar{\theta}-\frac{p_{1}-p_{2}}{k_{1}-k_{2}}\right)$. In what follows, we normalize the value of $\bar{\theta}$ to one.

Aggregate demand depends on consumers' beliefs about quality, i.e., consumers' information about the origin of the product. According to Lusk et al. (2006), “...consumers will make an assumption about the average quality of the product on the market. Because the market will contain products from a variety of origins, the expected quality of the product on the market might fall well below the perceived quality of the domestic product (p. 286)." Therefore, we assume that, without COOL, consumers believe the product is of expected quality $\bar{k}$, while with COOL, consumers relate origin information to their perceived quality, denoted by $k_{H}$ and $k_{L}$. We assume that with asymmetric information in the unlabeled market, consumers evaluate 
quality using a weighted average: $\bar{k}=\alpha k_{H}+\left(1-\alpha k_{L}\right)$, where $\alpha$ represents the proportion of unlabeled product that is perceived to be of high-quality by consumers.

\section{Pre-MCOOL Scenario 1: No COOL}

When there is no COOL, origin and production method cannot be determined by consumers; there is imperfect information in the market. Further, there is asymmetric information as sellers are aware of the origin and production of the product while consumers are not. We assume that, without labeling, consumers have no information about quality. In this situation, sellers do not have an incentive to sell domestic product and only the foreign product is sold. ${ }^{8}$

The retail and foodservice sectors are separated for the purpose of comparison with the other scenarios (see Panel 1, Figure 1). Consumer utility is identical in both markets, expected quality is $\bar{k}$ as defined above, and a unique price $\bar{p}$ develops. Table 1 shows the indirect utility of a consumer with preference parameter $\theta$ in the retail and foodservice market for one unit of product. In the inverse demand equation, $Q_{0}$ represents the quantity of good $\bar{k}$.

To determine the equilibrium quantities and prices without labeling, we first solve the profit-maximization problem for the retail and foodservice sectors (see table 1). Then, derived demands from the retail and foodservice sectors are equated with the supply of foreign firms. Each sector is characterized by $M$ identical firms and $q_{0 m}$ represents the quantity of an

\footnotetext{
${ }^{8}$ In the absence of origin information, domestic and foreign products are marketed together and the price received by establishments is the same regardless of which product is produced (pooling equilibrium; see Akerlof 1970). The absence of a premium for domestic product without segregation, coupled with higher costs of production, result in a lower profitability of the domestic product relative to the foreign product. In this case, the supply of domestic product is not incentive compatible; market forces lead to failure of the market to satisfy expressed consumer demands. Hence, only foreign product is sold in the unlabeled sector.
} 
individual retailer or foodservice establishment. We assume the retail and foodservice sectors incur the same procurement costs of the foreign product and other costs are assumed away.

The parameter $\lambda$ in the firms' demand equation corresponds to $1+\eta$ where $\eta$ represents the conjectural variation elasticity for an individual firm. Because we assume identical firms, the conjectural variation elasticity is identical in equilibrium and corresponds to $\eta=\frac{\partial Q_{0}}{\partial q_{0}} \frac{q_{0}}{Q_{0}}$. When $\eta$ is zero, firms have no market power, while $\eta=1$ implies perfect collusion, i.e., $\eta \in[0,1]$.

Equating derived demand facing the foreign firms, aggregated over retail and foodservice sectors, with supply and solving for $w_{L}$ gives the equilibrium input price (see table 1 ). The expressions for the equilibrium price and quantity can be obtained by substituting $w_{L}^{*}$ in the firms' and consumers' demand equations:

$$
\begin{aligned}
& Q_{0}^{*}=\frac{\bar{k}}{\bar{k} \lambda+2 c_{L}} \\
& \bar{p}^{*}=\frac{\left(\bar{k} \eta+2 c_{L}\right) \bar{k}}{\bar{k} \lambda+2 c_{L}}
\end{aligned}
$$

where $Q_{0}^{*}$ is the equilibrium quantity in each of the retail and foodservice sectors.

The consumer surplus in each sector is $C S^{N C}=\int_{\theta_{0}^{*}}^{1}\left(\theta \bar{k}-\bar{p}^{*}\right) d \theta=\bar{k}^{3} / 2\left(\bar{k} \lambda+2 c_{L}\right)^{2}$, where $\theta_{0}^{*}$ is the indifferent consumer in equilibrium. Expected consumer welfare in the two sectors is:

$$
C S^{N C}=\frac{\bar{k}^{3}}{\left(\bar{k} \lambda+2 c_{L}\right)^{2}}
$$

Equation (5) shows that consumer welfare depends positively on the expected quality and negatively on the production cost of the low-quality product and the level of market power. 
We also compute real consumer surplus. Real consumer surplus considers that while consumers believe the product is of quality $\bar{k}$, it is in fact $k_{L}$. Defining $\Delta k$ as $k_{H}-k_{L}$, the aggregate real consumer surplus for the same set of consumers and prices in equilibrium is:

$$
C S_{\mathrm{Re} a l}^{N C}=\frac{\bar{k}\left[\bar{k} k_{L}-2 \alpha \Delta k\left(\bar{k} \eta+2 c_{L}\right)\right]}{\left(\bar{k} \lambda+2 c_{L}\right)^{2}} .
$$

Profit earned by retail and foodservice sectors can be calculated by substituting equilibrium prices and quantities into the profit equations (table 1). The expression for profit aggregated over retail and foodservice sectors is:

(7) $\quad \Pi^{N C}=\frac{2 \bar{k}^{3} \eta}{\left(\bar{k} \lambda+2 c_{L}\right)^{2}}$

Equation (7) shows that profit depends positively on the expected quality of the product and the market power parameter, and negatively on the costs of producing low-quality product. Total domestic welfare is the summation of real consumer surplus, domestic producer surplus and profit. Domestic producer surplus is zero here because we assume sellers have no demand for domestic product in the absence of labeling.

(8) $T W^{N C}=\frac{\left.\bar{k}\left[\bar{k} k_{L}(1+2 \eta)-4 \alpha \Delta k c_{L}\right)\right]}{\left(\bar{k} \lambda+2 c_{L}\right)^{2}}$

\section{Pre-MCOOL Scenario 2: Voluntary COOL at Retail}

Prior to the implementation of MCOOL, some retailers may have voluntarily disclosed origin information for domestic product and may have chosen not to provide information about foreign product whose value to consumers may be less than its associated disclosure cost. Disclosing information about domestic product may be especially valuable when consumers have a strong 
willingness to pay for domestic product. The retailer can then segment the market and implement second-degree price discrimination. We examine this case as an alternative benchmark scenario.

In the retail sector of this scenario, the domestic product (labeled) is indexed by perceived quality $k_{H}$ whereas unlabeled product is indexed by expected quality $\bar{k}$. Again let us consider two firms, domestic and foreign, selling to two sectors, retail and foodservice (see Panel 2, Figure 1). We assume that the domestic product is supplied to retail only because it is labeled and foreign product is supplied to both the foodservice (unlabeled sector) and the retail sector, where it is not labeled. Table 1 shows the indirect utility of a consumer buying one unit of domestic product, or product of expected quality $\bar{k}$. The utility is zero is nothing is consumed. From there, we can derive the equation for the inverse demand of each product in each market, which are used in the profit-maximizing expressions. Retailers incur the costs associated with labeling domestic product (denoted by $b$ ).

Labeling also entails costs upstream. Domestic producers/harvesters and intermediaries incur the cost of establishing and maintaining a recordkeeping system for origin and production information, and for product identification, labor, and training (denoted by $y$ ). The supply of foreign firms remains unchanged. See table 1 for the resulting equilibrium input prices.

Consumer surplus in the retail and foodservice sectors, identified by subscript $r$ for retail and $f$ for foodservice, are calculated as:

$$
\begin{aligned}
& C S_{r}^{V C}=\int_{\theta_{0}^{*}}^{\theta_{H}^{*}}\left(\theta \bar{k}-\bar{p}^{*}\right) d \theta+\int_{\theta_{H}^{*}}^{1}\left(\theta k_{H}-p_{H}^{*}\right) d \theta \\
& C S_{f}^{V C}=\int_{\theta_{0}^{*}}^{1}\left(\theta \bar{k}-\bar{p}^{*}\right) d \theta
\end{aligned}
$$


where $\theta_{0}^{*}$ and $\theta_{H}^{*}$ are the equilibrium expressions of the consumers indifferent between buying nothing and buying $k_{L}$, and between the low- and high-quality product, respectively.

Total welfare includes the producer surplus of domestic firms (in addition to real consumer surplus, and profit), which is given by $P S_{D}=\left(w_{H}^{*}\right)^{2} / 2\left(c_{H}+y\right)$. Given the nonlinearity of the expressions for this and the next scenarios, the comparative statics with respect to quality and other parameters are performed numerically in the analysis section.

\section{Scenario 3: Partial MCOOL Implementation at Retail}

Partial MCOOL implementation may take alternative forms. The scenario here reflects partial MCOOL implemented under U.S. regulations for seafood, which requires labeling only for fresh and frozen seafood in retail. More generally, MCOOL is frequently implemented on a partial basis. For example, in the United States commodities subject to MCOOL in fresh form (e.g., muscle cuts of meat, ground meat, fruits, vegetables, and peanuts) do not require labeling in processed form under COOL rules, although tariff labeling rules may apply. Retailers convey product quality information to consumers via origin labels and a separating equilibrium may be attained that efficiently sorts consumers into markets for different qualities with corresponding prices. However, in the absence of labeling in the foodservice sector, only foreign product is supplied. Conversely, domestic product $\left(k_{H}\right)$ is supplied to retail because it is identifiable through labels. Foreign product $\left(k_{L}\right)$ is supplied to both the unlabeled foodservice sector and the labeled retail sector, where it is labeled as such. Panel 3 of Figure 1 shows how partial MCOOL facilitates quality differentiation at retail. Table 2 shows the expressions for this scenario.

With partial MCOOL, retailers incur costs of labeling, $b$, for both domestic and foreign product. In the voluntary case we assumed retailers voluntarily disclosed origin information 
about domestic product only ( $b$ applied to only domestic product). Given the Tariff Act of 1930 (see previous discussion), domestic firms bear operating costs (segregation and identity preservation costs) $y$ whereas foreign firms do not. Welfare measures are derived as in the voluntary COOL scenario and the expressions are analyzed numerically.

\section{Scenario 4: Total MCOOL Implementation at Retail and Foodservice}

In the final scenario, MCOOL is implemented in both the retail and foodservice sectors. There is no informational asymmetry, consumers are able to determine the origin of the product and make informed choices in both sectors. An important outcome of uniform regulation is the lack of scope for diversion. Panel 4 of Figure 1 illustrates this scenario. Labeling cost $b$ is applicable to both the foodservice and retail establishments. As before, cost $y$ is borne only by the domestic firms. The relevant expressions are shown in table 2. Welfare measures are computed as in the voluntary COOL and partial MCOOL scenarios. However, expected consumer surplus is the same as real consumer surplus in a totally differentiated market as there is no mismatch between quality of the product supplied and consumed.

\section{Comparative Welfare Under Four COOL Scenarios}

In this section, we solve for the first stage of the pre-MCOOL game (the other stages having already been solved) to understand under what conditions retailers would choose to voluntarily label the high-quality product or leave it unlabeled. Then we examine the extent to which diversion occurs as a result of partial MCOOL implementation. Finally, we evaluate the effect of partial and total MCOOL on welfare. More specifically, we are interested in determining the extent to which the strength of preference for the domestic product affects the level of diversion and welfare under the various labeling scenarios. 
Due to the complexity of the equilibrium expressions for profit and welfare, i.e., quality appears to the fourth power, we are unable to examine the effect of quality analytically. Thus, we turn to numerical solutions with Mathematica 8.0. We calibrate the model by normalizing $k_{L}$ to 1 , set costs associated with labeling to $b=0.02$ and $y=0.0025$, and then determine values for $\alpha$ and $k_{H}$ in the feasible region (positive prices and quantities in equilibrium). Costs of production are functions of quality, i.e., $c_{i}=0.5 k_{i}^{2}$ where $i=H, L$. We vary labeling costs $b$ from 0.01 to 0.1 for $k_{H}=1.1$ to analyze the incentive for retailers to voluntarily label domestic product relative to the no COOL scenario. We also vary $\eta$ from 0.1 to 1 to see the effect of market power on retailer profit and real consumer surplus. To analyze the effect of quality on welfare and diversion within the feasible region, we vary $k_{H} / k_{L}$ from 1.1 to 2.1 and $\alpha$ from 0.1 to 0.9 . $^{9}$ Table 3 shows equilibrium price and quantity for the four COOL scenarios for fixed parameter values.

\section{a. First stage of pre-MCOOL game}

In stage 1 of the pre-MCOOL game, retailers choose whether to label the high-quality product or not. The retailer voluntarily labels the product if it is profit maximizing to do so. Thus, there is one benchmark scenario (voluntary COOL or no COOL) that prevails for each set of parameter values. To evaluate the conditions under which each of the two benchmark scenarios dominates, we examine the effect of relative quality and labeling costs on the retailers' profit.

Given our model assumptions and the feasible range of parameter values, retailers always prefer voluntary COOL to no COOL over the quality range studied (Figure 2) and over the labeling costs range studied (Figure 3 ). ${ }^{10}$ Labeling the high-quality product is profitable because

\footnotetext{
${ }^{9}$ Note when $\alpha=0, \bar{k}=k_{L}$ and when $\alpha=1, \bar{k}=k_{H}$

${ }^{10}$ In figure 3, we set $k_{H}$ at a low value (1.1) to try to achieve a situation where no COOL is more profitable for retailers. We also examine values of $k_{H}$ as low as 1.01 (i.e., almost no quality difference with $k_{L}$ ) and found no change in ranking of voluntary and no COOL scenarios. One way to explore the no COOL scenario as a benchmark
} 
the retailer benefits from price discrimination between the labeled and unlabeled segments in voluntary COOL. We will henceforth consider voluntary COOL as the benchmark in discussing the welfare effects of partial and total MCOOL.

\section{b. Diversion}

Diversion can be related to the concept of 'leakage' in the emissions-leakage literature. Leakage refers to increases in production and associated emissions by unregulated producers that occur as a direct consequence of incomplete environmental regulation (CCAP, 2005; and RGGI, 2007). According to Fowlie (2009), when pollution regulation is applied to only a subset of firms in a polluting industry, substantial leakage may occur if production at unregulated firms can be substituted for regulated production. The increase in emissions by unregulated producers is a result of the increase in production costs of regulated firms.

Similarly, the partial implementation of MCOOL may lead to diversion or leakage of lower quality imports to the unlabeled sector. Diversion occurs in partial MCOOL because both domestic and foreign products need to be labeled only in the retail market. There is diversion because of 1) the increase in costs associated with labeling, and 2) the change in consumption when consumers are informed about quality. Similar to Fowlie (2009), we define diversion as the difference between the quantity of foreign product sold to the foodservice sector under incomplete regulation (partial MCOOL) and under no regulation (either no or voluntary COOL).

We examine the effect of partial MCOOL on the quantity of low-quality product diverted to the unlabeled market, i.e., the foodservice market in our model. Before MCOOL implementation, neither retail nor foodservice markets are required to be labeled. If low-quality products are not labeled, there is no potential for diversion. However, with mandatory labeling of the labels. The no COOL scenario is characterized by retailers selling foreign products only. 
high- and low-quality product only in the retail market under partial MCOOL, low-quality product may be diverted to the unlabeled (foodservice) market. One way to measure diversion to the unlabeled market is to compare the quantity of low-quality product sold to the foodservice market (unlabeled) when there is voluntary COOL, i.e., $Q_{0}^{* V C}$, with the quantity sold under partial MCOOL, i.e., $Q_{0}^{* P C}{ }^{11}$ Substituting parameter values, the quantity sold to the foodservice sector under voluntary COOL is smaller than under implementation of the law (see table 3, $0.498<0.516)$. This indicates diversion of low-quality product to the unlabeled market under partial MCOOL. However, this measure may be misleading because it is possible that the total quantity of product sold in the retail and foodservice markets (high- and low-quality) increases with partial MCOOL. Thus, a relative measure of diversion is more accurate.

Diversion is measured by comparing the relative quantity of low-quality product sold in the foodservice sector under partial MCOOL to the relative quantity sold with voluntary COOL:

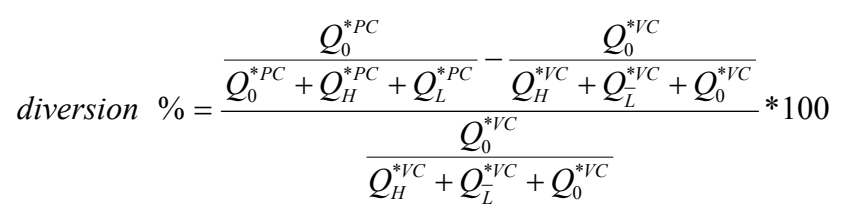

It is expressed as the relative difference between the share of low-quality product sold in foodservice pre- and post-partial MCOOL implementation (see Figure 4 for visualization).

We find evidence of diversion. For the set of parameter values in table 3, diversion is $5.2 \%$. This means that there is some diversion of low-quality product to the foodservice market under partial MCOOL when compared to voluntary COOL. Under partial MCOOL, the pricequality ratio of the product in the foodservice sector is lower than under voluntary COOL. Therefore, unlabeled product from the food service market under partial MCOOL is more

\footnotetext{
${ }^{11}$ Note that similar calculations can be done with no COOL as benchmark. We choose to present only the diversion measure under the prevailing benchmark (voluntary COOL).
} 
attractive to consumers. This can be explained as follows. In the voluntary COOL case consumers expect the unlabeled product to be of quality $\bar{k}$. With partial MCOOL, low-quality foreign product supplied to the retail market is labeled whereas the unlabeled sector behaves similarly to the voluntary COOL case. Price competition between domestic and foreign product in the partial MCOOL scenario results in a lower price for product of quality $\bar{k}$ in the unlabeled sector than in the voluntary COOL case. Thus, the quantity of low-quality product sold in the unlabeled sector after partial MCOOL implementation is greater than with voluntary COOL.

Figure 5 shows that the greater the quality differences (real or perceived) between domestic and foreign product, the greater will be the diversion to the unlabeled market. Further, we can show that diversion increases as $\alpha$, the proportion of unlabeled product that is perceived to be of high quality by consumers, increases. Diversion increases with $\alpha$ because consumers are willing to pay more for unlabeled product, which makes foodservice a more profitable market segment. These results are important for policy purposes. They indicate that incomplete regulation will be more of an issue in terms of diversion, the more consumers 1) perceive the domestic products to be significantly superior in quality to foreign products, i.e., $k_{H} / k_{L}$ is large and/or 2) perceive the unlabeled product to be of higher quality than it really is, i.e., $\alpha$ is large.

\section{c. Retailer and Foodservice Profit}

Figure 2 shows that, over the range of quality differences studied, the two MCOOL scenarios result in lower profits for the retailer relative to voluntary COOL. An unlabeled market (such as for retailers in voluntary COOL) helps sellers take advantage of consumer misinformation by masquerading low-quality product as higher quality. As a result, consumers pay a higher price 
for product that is in fact of low quality to the benefit of retailers. ${ }^{12}$ This is not possible under MCOOL as both domestic and foreign product sold at retail must be labeled. Figure 3 shows that as labeling costs increase, retailers' profit decreases more under partial and total MCOOL than under voluntary COOL because both domestic and foreign product must be labeled.

Figures $6 \mathrm{a}$ and $6 \mathrm{~b}$ show that foodservice profit increases with perceived product differentiation for all labeling scenarios. In figure $6 \mathrm{a}, \alpha$, the proportion of unlabeled product that is perceived to be of high quality by consumers, is low and the quality misperception for unlabeled products is small. At this low $\alpha$, total MCOOL results in greater foodservice profit than in the other scenarios. This occurs because foodservice firms benefit from product differentiation and the associated price discrimination under total MCOOL, while the benefits from consumer misperception in the other scenarios (partial MCOOL and voluntary COOL) are small when $\alpha$ is low. Figure $6 \mathrm{~b}$ shows that at high $\alpha$, foodservice profits are highest under partial MCOOL because diversion results in greater quantity sold in foodservice under partial than voluntary COOL.

In summary, based on profits retailers always prefer to voluntarily label products, while foodservice operators prefer partial MCOOL when consumers' misperception about the quality of unlabeled product is high enough. Both sectors benefit from the asymmetry in information. Table 4 shows retailer and foodservice profits under the four scenarios at fixed parameter values.

\section{d. Consumer surplus}

Table 4 shows the comparative magnitude of consumer surplus (expected and real) across the pre- and post-MCOOL scenarios for fixed parameter values. At these specified values, expected consumer surplus is greatest under the benchmark scenario, i.e., voluntary COOL. Expected

\footnotetext{
${ }^{12}$ In fact, we show that as the misperception of the quality of the unlabeled product, $\alpha$, increases, the retailer's profit under voluntary COOL increases relative to partial MCOOL and total MCOOL.
} 
consumer welfare in voluntary COOL and partial MCOOL do not take into account the real quality $k_{L}$ of foreign product supplied to consumers in the non-labeled sector. Rather it is based on consumers' belief of quality $\bar{k}$, where $k_{L} \leq \bar{k} \leq k_{H}$. Thus, while consumers expect they are getting $\bar{k}$, they are in fact consuming product of lower quality (unless $\bar{k}=k_{L}$ ). Because consumer utility is dependent on the quality of the product consumed, consumer surplus is necessarily higher when consumers believe they are getting $\bar{k}$ rather than $k_{L}$, as occurs in partial MCOOL in the foodservice sector and in voluntary COOL in both the retail and foodservice sectors. Real consumer surplus is greatest with total MCOOL when consumers are aware of the quality of the product they consume and can make informed choices.

We are interested in the impact of perceived quality difference between domestic and foreign product on real consumer surplus. We find that the effect of quality differentiation depends on the extent to which consumers misperceive (overestimate) the quality of the unlabeled product, i.e., the size of $\alpha$. Thus, we examine the effect of quality differentiation on real consumer surplus when the misperception is small $(\alpha=0.1)$ and when it is large $(\alpha=0.9)$.

When consumers correctly perceive the unlabeled product to be of low-quality (e.g., $\alpha=$ 0.1 , figure $7 \mathrm{a}$ ), there is no increase in real consumer surplus with partial MCOOL (relative to voluntary COOL). Real consumer surplus increases with total MCOOL.

When consumers incorrectly perceive the unlabeled product to be of quality comparable to that of the domestic product (e.g., $\alpha=0.9$, figure $7 \mathrm{~b}$ ), there is an increase in real consumer surplus with total MCOOL when compared to voluntary COOL and partial MCOOL. Total MCOOL removes the distortion in the market caused by 1) consumers' misperception of product quality when the product is unlabeled, and by 2) the presence of sellers with market power taking 
advantage of the information asymmetry. Even at $\alpha=0.5$, the increase in consumer welfare is much larger under total MCOOL (22.5\% increase using data from table 4) than under partial MCOOL (3.7\% increase).

As perceived product differentiation increases, real consumer surplus decreases for the voluntary COOL and partial MCOOL scenarios when $\alpha$ is high (e.g., when $\alpha=0.9$, figure 7b) because, in unlabeled sectors consumers choose quantity on the basis of expected quality $\bar{k}$, but in fact are consuming $k_{L}$. For $\alpha=0.9$, as $k_{H}$ increases, $\bar{k}$ increases, which increases the price $\bar{p}$ and reduces the quantity of (foreign) product consumed. Thus, real consumer surplus decreases under these scenarios as the price-quality ratio $\left(\bar{p} / k_{L}\right)$ increases with no change in real quality, and the quantity consumed decreases.

In summary, relative to voluntary $\mathrm{COOL}$, consumers are better off with a MCOOL regulation regardless of their quality perception of the unlabeled product. As expected, consumers benefit more from a complete regulation (total MCOOL) than an incomplete one (partial MCOOL). Regulation is especially beneficial to consumers the more they believe domestic products to be of superior quality than imported products, and the more they misperceive the unlabeled products to be of quality similar to the domestic product. Note also that when both are true (i.e., large $k_{H} / k_{L}$ and high $\alpha$ ), the increase in consumer welfare is much larger from total than partial MCOOL. This has important implications for policymaking. If the regulator ignores the presence of an exempted market, the benefit to consumers from the regulation will be much smaller than anticipated.

\section{e. Domestic producer surplus and total welfare}


Overall, both MCOOL scenarios increase the welfare of domestic producers relative to voluntary COOL, with the greatest increase coming from total MCOOL (table 4). Summing across sectors, table 3 shows the quantity of domestic product supplied to the labeled sectors (retail and foodservice) is greatest under total MCOOL, followed by partial MCOOL and voluntary COOL. When $\alpha$ is low (figure 8a), domestic producers would not gain much from a partial regulation relative to voluntary COOL, whereas they would significantly benefit from total MCOOL, if the quality difference was important. However, if $\alpha$ is large (figure $8 b$ ) and the quality difference is important, producers would also benefit from a partial MCOOL relative to voluntary COOL.

Total welfare has three components - profit of the retail and foodservice sectors, real consumer surplus, and domestic producer surplus. Figures $9 \mathrm{a}($ low $\alpha$ ) and $9 \mathrm{~b}$ (high $\alpha$ ) show that when there is little perceived quality differentiation between domestic and foreign products, there is no increase in total welfare for society from a labeling regulation relative to voluntary COOL, regardless of the level of quality misperception. With higher quality differentiation and low $\alpha$ (see figure 9a), there is an increase in total welfare with total MCOOL relative to partial MCOOL or voluntary MCOOL, with society being indifferent based on total welfare between partial and voluntary labeling. For high $k_{H} / k_{L}$ and high $\alpha$ (figure $9 \mathrm{~b}$ ), based on total welfare both types of MCOOL would be preferred over voluntary labeling. As perceived quality differentiation increases with high $\alpha$, total welfare increases for partial and total MCOOL but not for voluntary COOL. For partial MCOOL, the increase in total welfare occurs despite a decrease in real consumer surplus with increasing $k_{H}$. Total welfare increases in partial MCOOL because retailer and foodservice profit and domestic producer surplus together overweigh real consumer surplus regardless of perceived quality differentiation and consumer misperception of the quality 
of unlabeled product. ${ }^{13}$ Total welfare is highest under total MCOOL, particularly when the perceived quality differentiation between the domestic and foreign product is high and regardless of the level of quality misperception for the unlabeled product.

\section{f. Effect of market power on retail profit and real consumer surplus}

As expected, Figures 10a and 10b show that greater market power in the retail and food service sectors results in higher retailer profits and lower real consumer surplus under all scenarios when $\alpha$ is high. Our results (not illustrated here) also show that as consumers' misperception of quality of the unlabeled product increases, i.e., $\alpha$ increases, retailers benefit the most from greater market power under voluntary COOL (i.e., profits increase at a faster rate). That is, market power enhances the profitability of masquerading the unlabeled product as a high-quality one. ${ }^{14}$ Accordingly, consumers have the lowest real surplus under voluntary COOL, powerful retailers, and a high degree of quality misinformation (Figure 10b).

\section{Conclusion}

We develop a conceptual model of heterogeneous consumers with respect to taste for product quality and contribute a distinct focus on the economic impacts of incomplete labeling regulation. This investigation is motivated by the partial implementation of country-of-origin labeling (partial MCOOL) in the U.S. seafood market, where processed products and the foodservice sector are exempted from labeling. In this industry, the exempted market represents a large share of consumption.

Though motivated by the seafood industry, our model is general enough to understand the effects of partial labeling regulations in the other food markets in which partial MCOOL has

\footnotetext{
${ }^{13}$ These result also hold with higher levels of market power, i.e., $\eta=1$ or perfect collusion.

${ }^{14}$ To visualize the effect of an increase in $\alpha$ from 0.5 to 0.9 on retail profits, compare the vertical distance between the curves representing the various scenarios at $k_{H} / k_{L}=1.5$ in figure 2, and the same at $\eta=0.5$ in Figure 10a.
} 
been implemented. It also applies to other types of mandatory labeling where the perceived lowquality product is required to be labeled, such as the labeling of GM food in some countries. Whenever a low-quality product is required to be labeled, but exemptions are granted, there is potential for diversion of the low-quality product into unlabeled market segments.

We show that combining the effects of diversion, imperfect competition, and information asymmetry can lead to the regulation having unexpected welfare effects. Namely, relative to the status quo (voluntary COOL), the exempted market (foodservice) is an important beneficiary of the incomplete regulation. Diversion to the exempted market under partial MCOOL increases the quantity marketed by sellers who capitalize on consumer misinformation by masquerading lowquality as average-quality product. Conversely, sellers in the labeled market (retail) are important losers from the partial regulation. Retailers lose from the diversion of low-quality product to the unlabeled market. Under partial MCOOL, they also lose from the inability to capitalize on consumers' misinformation. Unlike sellers in the foodservice market, retailers experience lower profits under partial MCOOL than under voluntary COOL.

We also demonstrate that if consumers do not perceive the product to be differentiated by country of origin, imposing MCOOL regulation, in either a complete or incomplete form, will lead to no or minor increases in real consumer welfare relative to voluntary COOL. However, for markets or products for which quality differentiation is perceived to be high enough by consumers, partial or total MCOOL is preferable relative to voluntary COOL for consumers as it allows them to sort qualities and make decisions according to their willingness to pay. Mandatory labeling (either partial or total) is beneficial because it means that less product goes unlabeled. The lack of required labeling causes market distortion that becomes more important as perceived product differentiation increases when 1) consumers believe the unlabeled product is 
of higher quality than what it truly is, and 2) sellers with market power take advantage of the information asymmetry. If regulators adopt partial MCOOL while ignoring the exempted market and the resulting diversion of product into it, the positive impact on real consumer welfare will be much smaller than they anticipate.

In fact, we show that if consumers do indeed perceive a sizable quality difference between the high-quality (domestic) and low-quality (imported) product, total MCOOL yields the highest real welfare for consumers, high-quality domestic producers, and the overall domestic market. If total MCOOL is too costly to implement, our results suggest that partial MCOOL is the second-best solution but only if consumers' misperception about the quality of the unlabeled product is large enough. In other words, as perceived product differentiation increases and consumers falsely believe that unlabeled product is of high-quality, regulation, even in a partial fashion, can increase real consumer and overall domestic welfare.

If the goal of MCOOL is to benefit consumers, policy makers need to be sure that consumers indeed value the information provided. In the context of our model and MCOOL, it is important to know the extent to which consumers view domestic product as being of superior quality to imported products. Our results thus call for more research on consumers' willingness to pay for domestic product and for more surveys of the type conducted by Klain et al. (2011). In addition, it is important to know what assumptions consumers make about the quality of unlabeled products. These assumptions impact the degree to which they misperceive quality and the degree to which labeling would improve their information. When domestic products are perceived by consumers to be significantly superior in quality to foreign products, policy makers also need to be aware that incomplete regulation can lead to diversion and lower than anticipated consumer welfare effects. 


\section{References}

Akerlof, G. A. 1970. "The market for 'lemons': Quantitative uncertainty and the market mechanism.” Quarterly Journal of Economics Vol. 89, pages 488-500.

Allshouse, J., J. Buzby, D. Harvey, and D. Zorn. 2004. "Seafood Safety and Trade", Issues in Diet, Safety, and Health. Agriculture Information Bulletin, no.789-7, USDA, Economic Research Service, February.

Awada, L., and A. Yiannaka. 2012. "Consumer perceptions and the effects of country of origin labeling on purchasing decisions and welfare." Food Policy Volume 37, Issue 1, February

Brester, G. W., Marsh, J. M., and J. A. Atwood 2004. "Distributional impact of country-of-origin labeling in the U.S. meat industry". Journal of Agricultural and Resource Economics, $29(2), 206-227$.

Bureau, J. C., Marette, S., and A. Schiavina. 1998. "Non-tariff Trade Barriers and Consumers' Information: The Case of the E.U.-U.S. Trade Dispute over Beef'. European Review of Agricultural Economics. Vol. 25, pages 437-462.Caswell, J. A. 2006. "Quality Assurance, Information Tracking, and Consumer Labeling”. Marine Pollution Bulletin. Vol. 53, Issues 10-12, pages 650-656.

Cavanaugh, B. B. 2003. "Mexican shrimp make a big splash on seafood menus". Nation's Restaurant News. New York: Sept 22. Vol. 37, Iss. 38, p. 83, 152+

Center for Clean Air Policy. 2005. "Design of a Cap on Emissions from California Power Demand," Technical Report, CCAP 
Center for Disease Control and Prevention, 2012. "CDC Research Shows Outbreaks Linked to Imported Foods Increasing." http://www.cdc.gov/media/releases/2012/p0314_foodborne.html

Chanjin, C., Zhang, T., and D. S. Peel. 2009. "Effects of Country of Origin Labeling in the U.S. Meat Industry with Imperfectly Competitive Processors", Agricultural and Resource Economics Review Vol. 38, No. 3, pages 406-417.

Consumer Reports, 2007. http://greenerchoices.org/pdf/Food\%20Labeling\%20Poll-final_rev.pdf

Federal Register (2009). Mandatory Country of Origin Labeling of Beef, Pork, Lamb, Chicken, Goat Meat, Wild and Farm-Raised Fish and Shellfish, Perishable Agricultural Commodities, Peanuts, Pecans, Ginseng, and Macadamia Nuts. Final Rule. Department of Agriculture, Agricultural Marketing Services, 7 CFR Parts 60 and 65 . http://www.ams.usda.gov/AMSv1.0/getfile?dDocName=STELPRDC5074925

Fowlie, M. (2009). "Incomplete Environmental Regulation, Imperfect Competition, and Emissions Leakage". American Economic Journal: Economic Policy, Vol. 1, No. 2, pages $72-112$.

Fulton, M., and K. Giannakas. 2004. "Inserting GM products into the Food Chain: The Market and Welfare Effects of different Labeling and Regulatory Regimes," American Journal of Agricultural Economics. Vol. 86, Issue. 1, pages 42- 60.

Gao, Z., and T.C. Schroeder. 2009. "Effects of Label Information on Consumer Willingness-to Pay for Food Attributes." American Journal of Agricultural Economics 91(3):795-809.

Giannakas, K., and M. Fulton. 2002. "Consumption Effects of Genetic Modification: What if consumers are right? Agricultural Economics Vol. 27, pages 97-109. 
Gruère, G.P., and S.R. Rao, 2007.“A Review of International Labeling Policies of Genetically Modified Food to Evaluate India's Proposed Rule." AgBioForum 10(1): 51-64. http://agbioforum.org/v10n1/v10n1a06-gruere.htm.

Hammonds, T. 2003. "Retailer Expectations for Country-of-Origin Labeling”. Paper presented at AAEA Food \& Agricultural Marketing Policy Section Conference Emerging Roles for Food Labels: Inform, Protect, Persuade. Washington, D.C., March 20-21.

Iqbal, J., R. Kim, and J. Rude. 2006. “This Little Piggy Went to Market with a Passport: The Impacts of U.S. Country of Origin Labeling on the Canadian Pork Sector". Canadian Journal of Agricultural Economics, Vol. 54, Issue 3, pages 401-420.

Johnecheck, Wendy A., Parke E. Wilde, and Julie A. Caswell. 2010. Market and Welfare Impacts of COOL on the US-Mexican Tomato Trade. Journal of Agricultural and Resource Economics Vol. 35, Issue 3, pages 503-521.

Jones, K. G., Somwaru, A., and J. B. Whitaker. 2009. “Country of Origin Labeling: Evaluating the Impacts on U.S. and World Markets." Agricultural and Resource Economics Review Vol. 38, Issue 3, pages 397-405.

Klain, T. J., Lusk, J. L., Tonsor, G. T., and T. C. Schroeder. 2011. "Valuing Information: The Case of Country of Origin Labeling." http://idei.fr/doc/conf/inra/papers_2011/lusk.pdf

Krissoff, B., F. Kuchler, K. Nelson, J. Perry, and A. Somwaru. 2004. "Country-of-Origin Labeling: Theory and Observation,” Outlook Report No. (WRS04-02), January.

Kuchler, F., Krissoff, B., and D. Harvey. 2010. "Do Consumers Respond to Country-of-Origin Labelling?" Journal of Consumer Policy 33(4):323-337.

Link, J.E. 2009. "Mandatory Country of Origin Labeling of Beef, Pork, Lamb, Chicken, Goat 
Meat, Wild and Farm-Raised Fish and Shellfish, Perishable Agricultural Commodities, Peanuts, Pecans, Ginseng, and Macadamia Nuts." The Federal Register / FIND 74(010):2658.

Loureiro, M.L. and W.J. Umberger. 2007. “A choice experiment model for beef: What US consumer responses tell us about relative preferences for food safety, country-of-origin labeling and traceability." Food Policy 32(4):496-514.

Lusk, J.L. and J.D. Anderson, 2004. "Effects of Country-of-Origin Labeling on Meat Producers and Consumers." Journal of Agricultural and Resource Economics, 29(2):185-205.

Lusk, J. L., Brown, J., Mark, T., Proseku, I., Thompson, R., Welsh, J. 2006. "Consumer Behavior, Public Policy, and Country-of-Origin Labeling”. Review of Agricultural Economics, Vol. 28, No. 2, pages 284-292.

Lusk, J.L. and S. Marette, 2012. "Can Labeling and Information Policies Harm Consumers?" Journal of Agricultural \& Food Industrial Organization, 10(1): 1542-0485, DOI: $10.1515 / 1542-0485.1373$

Meyer, S. R. 2008. "Implementation of Mandatory Country of Origin Labeling (MCOOL) in the Pork Industry," Choices, 23(4).

Mennecke, B.E., S.M. Lonergan, D.J. Hayes, and A.M. Townsend. 2007. “A Study of the Factors that Influence Consumer Attitudes toward Beef Products using the Conjoint Market Analysis Tool." Journal of Animal Science 85(10):2639-2659.

Miranda, M.J., and L. Kónya. 2006. "Is Mandatory Country-of-Origin Labelling a Retrograde Step in the Long Run?" International Review of Retail, Distribution \& Consumer Research 16(5):579-590. 
Mussa, M. and S. Rosen. 1978. "Monopoly and Product Quality". Journal of Economic Theory, Vol. 18, Issue 2, pages 301-317.

National Marine Fisheries Service. (NMFS) 2011 http://www.nmfs.noaa.gov/fishwatch/trade_and_aquaculture.htm (accessed Aug, 2011).

Peel, D. S. 2008. "Implementation of Country of Origin Labeling (COOL) in the Beef Industry," Choices, 23(4).

Plastina A., Giannakas, K., and D. Pick. 2011 "Market and Welfare Effects of Mandatory Country-Of-Origin-Labeling in the U.S. Specialty Crops Sector." Southern Economic Journal, Vol. 77, Issue 4.

Racino, B., 2011. "FDA Inspectors Not Keeping Pace with Food Imports." Washington Post, October 22, 2011. $\quad$ http://www.washingtonpost.com/national/health-science/fdainspectors-not-keeping-pace-with-imports/2011/09/19/gIQAITwo7L_story.html

Regional Greenhouse Gas Initiative Staff Working Group. 2007. "Potential emissions leakage and regional greenhouse gas initiative: Evaluating market dynamics, monitoring options, and possible mitigation options," Technical Report.

Saak, A., 2011. A Model of Labeling with Horizontal Differentiation and Cost Variability," American Journal of Agricultural Economics, Vol. 93, Issue 4, pages 11311150.

Stewart, H., N. Blisard, S. Bhuyan, and R. M. Nayga, Jr. 2004. "The demand for food away from home Full-service or Fast food?” USDA Agricultural Economic Report no. 829. January.

Umberger, W., D. Feuz, C. Calkins, and B. Sitz. 2003. “Country-Of-Origin Labeling of Beef Products: US Consumers' Perceptions.” Journal of Food Distribution Research 34(03). 
U.S. Department of Agriculture, Agricultural Marketing Service (USDA-AMS), 2004. "Mandatory Country of Origin Labeling of Fish and Shellfish; Interim Rule", Federal Register. Vol. 69(192), October 5.

VanSickle, J. 2008. "Country of Origin Labeling for Fruits and Vegetables," Choices, 23(4).

Verlegh, P. W. J. and J. E. M. Steenkamp. 1999. “A review and meta-analysis of country of origin research". Journal of Economics Psychology. Vol. 20, pages 521-46

Ward, R., D. Von Bailey, and R. Jensen. 2005. “An American BSE Crisis: Has it affected the Value of Traceability and Country-of-Origin Certifications for US and Canadian Beef?" International Food \& Agribusiness Management Review 8(2):92-114

Zago, A. M., and D. Pick. 2004. "Labeling Policies in Food Markets: Private Incentives, Public Intervention, and Welfare Effects", Journal of Agricultural and Resource Economics, Vol. 29 Issue 1, pages 150-165. 
Table 1: Relevant equations and results for the two pre-MCOOL scenarios: No COOL and Voluntary COOL

\begin{tabular}{|c|c|c|c|c|}
\hline & \multicolumn{2}{|c|}{ No COOL } & \multicolumn{2}{|c|}{ Voluntary COOL at Retail } \\
\hline & Retail & Food Service & Retail & Food Service \\
\hline Utility & $\theta \bar{k}-\bar{p}$ & $\theta \bar{k}-\bar{p}$ & $\begin{array}{l}\theta k_{H}-p_{H} \\
\theta \bar{k}-\bar{p}\end{array}$ & $\theta \bar{k}-\bar{p}$ \\
\hline $\begin{array}{l}\text { Inverse } \\
\text { consumer } \\
\text { demands }\end{array}$ & $\bar{p}=\bar{k}\left(1-Q_{0}\right)$ & $\bar{p}=\bar{k}\left(1-Q_{0}\right)$ & $\begin{array}{l}p_{H}=k_{H}-k_{H} Q_{H}-\bar{k} Q_{0} \\
\bar{p}=\bar{k}\left(1-Q_{H}-Q_{0}\right)\end{array}$ & $\bar{p}=\bar{k}\left(1-Q_{0}\right)$ \\
\hline $\begin{array}{l}\text { Profit } \\
\text { maximization } \\
\text { problem }\end{array}$ & $\begin{array}{l}\max _{q_{0 m}} \Pi_{m}= \\
{\left[\bar{p}\left(Q_{0}\right)-w_{L}\right] q_{0 m}}\end{array}$ & $\begin{array}{l}\max _{q_{0 m}} \Pi_{m}= \\
{\left[\bar{p}\left(Q_{0}\right)-w_{L}\right] q_{0 m}}\end{array}$ & $\begin{array}{l}\max _{q_{H}, q_{0 m}} \Pi_{r m}^{V C}= \\
{\left[p_{H}\left(Q_{H}, Q_{0}\right)-w_{H}-b\right] q_{H m}} \\
\left.+\bar{p}\left(Q_{H}, Q_{0}\right)-w_{L}\right] q_{0 m}\end{array}$ & $\begin{array}{l}\max _{q_{0 m}} \prod_{m}= \\
{\left[\bar{p}\left(Q_{0}\right)-w_{L}\right] q_{0 m}}\end{array}$ \\
\hline $\begin{array}{l}\text { Firm } \\
\text { demands }\end{array}$ & $Q_{0}=\left(\bar{k}-w_{L}\right) / \bar{k} \lambda$ & $Q_{0}=\left(\bar{k}-w_{L}\right) / \bar{k} \lambda$ & $\begin{aligned} Q_{H} & =\frac{(1-\alpha) \Delta k-b-w_{H}+w_{L}}{\lambda(1-\alpha) \Delta k} \\
Q_{0} & =\frac{\bar{k}\left(b+w_{H}\right)-k_{H} w_{L}}{\lambda(1-\alpha) \Delta k \bar{k}}\end{aligned}$ & $Q_{0}=\left(\bar{k}-w_{L}\right) / \bar{k} \lambda$ \\
\hline Supply & \multicolumn{2}{|c|}{$Q_{L}\left(w_{L}\right)=w_{L} / c_{L}$} & \multicolumn{2}{|c|}{$\begin{array}{c}Q_{H}\left(w_{H}\right)=w_{H} /\left(c_{H}+y\right) \\
Q_{L}\left(w_{L}\right)=w_{L} / c_{L}\end{array}$} \\
\hline $\begin{array}{l}\text { Equilibrium } \\
\text { input prices }\end{array}$ & \multicolumn{2}{|c|}{$w_{L}^{*}=\frac{2 \bar{k} c_{L}}{\bar{k} \lambda+2 c_{L}}$} & \multicolumn{2}{|c|}{$\begin{array}{c}w_{H}^{*}=\frac{\left(c_{H}+y\right)\left[\left(\lambda \bar{k}+2 c_{L}\right)\left(k_{H}-b\right)-\lambda \bar{k}^{2}\right]}{\left(\lambda \bar{k}+2 c_{L}\right)\left(\lambda k_{H}+c_{H}+y\right)-\lambda \bar{k}\left(\lambda \bar{k}+c_{L}\right)} \\
w_{L}^{*}=\frac{c_{L} \bar{k}\left\{\lambda[(1-\alpha) \Delta k+b]+2\left(c_{H}+y\right)\right\}}{\left(\lambda \bar{k}+2 c_{L}\right)\left(\lambda k_{H}+c_{H}+y\right)-\lambda \bar{k}\left(\lambda \bar{k}+c_{L}\right)}\end{array}$} \\
\hline
\end{tabular}


Table 2: Relevant equations and results for the two post-MCOOL scenarios: partial MCOOL and total MCOOL.

\begin{tabular}{|c|c|c|c|c|}
\hline & \multicolumn{2}{|c|}{ Partial MCOOL at Retail } & \multicolumn{2}{|c|}{ Total MCOOL at Retail and Foodservice } \\
\hline & Retail & Food Service & Retail & Food Service \\
\hline Utility & $\begin{array}{l}\theta k_{H}-p_{H} \\
\theta k_{L}-p_{L}\end{array}$ & $\theta \bar{k}-\bar{p}$ & $\begin{array}{l}\theta k_{H}-p_{H} \\
\theta k_{L}-p_{L}\end{array}$ & $\begin{array}{l}\theta k_{H}-p_{H} \\
\theta k_{L}-p_{L}\end{array}$ \\
\hline $\begin{array}{l}\text { Inverse } \\
\text { consumer } \\
\text { demands }\end{array}$ & $\begin{array}{l}p_{H}=k_{H}-k_{H} Q_{H}-k_{L} Q_{L} \\
p_{L}=k_{L}\left(1-Q_{H}-Q_{L}\right)\end{array}$ & $\bar{p}\left(Q_{0}\right)=\bar{k}\left(1-Q_{0}\right)$ & $\begin{array}{l}p_{H}=k_{H}-k_{H} Q_{H}-k_{L} Q_{L} \\
p_{L}=k_{L}\left(1-Q_{H}-Q_{L}\right)\end{array}$ & $\begin{array}{l}p_{H}=k_{H}-k_{H} Q_{H}-k_{L} Q_{L} \\
p_{L}=k_{L}\left(1-Q_{H}-Q_{L}\right)\end{array}$ \\
\hline $\begin{array}{l}\text { Profit max. } \\
\text { problem }\end{array}$ & $\begin{array}{l}\max _{q_{H m}, q_{L m}} \prod_{r}^{P C}= \\
{\left[p_{H}\left(Q_{H}, Q_{L}\right)-w_{H}-b\right] q_{H m}} \\
+\left[p_{L}\left(Q_{H}, Q_{L}\right)-w_{L}-b\right] q_{L m}\end{array}$ & $\max _{q_{0 m}} \prod_{m}=\left[\bar{p}\left(Q_{0}\right)-w_{L}\right] q_{0 m}$ & $\begin{array}{l}\max _{q_{H m}, q_{L m}} \prod_{r}^{P C}= \\
{\left[p_{H}\left(Q_{H}, Q_{L}\right)-w_{H}-b\right] q_{H m}} \\
+\left[p_{L}\left(Q_{H}, Q_{L}\right)-w_{L}-b\right] q_{L m}\end{array}$ & $\begin{array}{l}\max _{q_{H m}, q_{L m}} \prod_{r}^{P C}= \\
{\left[p_{H}\left(Q_{H}, Q_{L}\right)-w_{H}-b\right] q_{H m}} \\
+\left[p_{L}\left(Q_{H}, Q_{L}\right)-w_{L}-b\right] q_{L m}\end{array}$ \\
\hline $\begin{array}{l}\text { Firm } \\
\text { demands }\end{array}$ & $\begin{aligned} Q_{H} & =\frac{\Delta k-w_{H}+w_{L}}{\lambda \Delta k} \\
Q_{L} & =\frac{w_{H} k_{L}-w_{L} k_{H}-b \Delta k}{\lambda \Delta k k_{L}}\end{aligned}$ & $\bar{Q}=\left(\bar{k}-w_{L}\right) / \bar{k} \lambda$ & $\begin{aligned} Q_{H} & =\frac{\Delta k-w_{H}+w_{L}}{\lambda \Delta k} \\
Q_{L} & =\frac{w_{H} k_{L}-w_{L} k_{H}-b \Delta k}{\lambda \Delta k k_{L}}\end{aligned}$ & $\begin{aligned} Q_{H} & =\frac{\Delta k-w_{H}+w_{L}}{\lambda \Delta k} \\
Q_{L} & =\frac{w_{H} k_{L}-w_{L} k_{H}-b \Delta k}{\lambda \Delta k k_{L}}\end{aligned}$ \\
\hline Supply & \multicolumn{2}{|c|}{$\begin{array}{c}Q_{H}\left(w_{H}\right)=w_{H} /\left(c_{H}+y\right) \\
Q_{L}\left(w_{L}\right)=w_{L} / c_{L}\end{array}$} & \multicolumn{2}{|c|}{$\begin{array}{c}Q_{H}\left(w_{H}\right)=w_{H} /\left(c_{H}+y\right) \\
Q_{L}\left(w_{L}\right)=w_{L} / c_{L}\end{array}$} \\
\hline $\begin{array}{l}\text { Equilibrium } \\
\text { input price }\end{array}$ & \multicolumn{2}{|c|}{$\begin{array}{c}w_{H}^{*}=\frac{\left(c_{H}+y\right)\left[B+c_{L} \bar{k}\left(k_{L}-b\right)\right]}{A\left(\bar{k} k_{L} \lambda+c_{L} k_{L}\right)+c_{L} \bar{k}\left(\lambda k_{H}+c_{H}+y\right)} \\
w_{L}^{*}=\frac{c_{L} \bar{k}\left[A\left(k_{L}-b\right)+k_{L}\left(c_{H}+y\right)\right]}{A\left(\bar{k} k_{L} \lambda+c_{L} k_{L}\right)+c_{L} \bar{k}\left(\lambda k_{H}+c_{H}+y\right)} \\
A=\lambda \Delta k+c_{H}+y \\
B=\bar{k}_{L} \lambda \Delta k+c_{L}\left(\bar{k}_{H}+k_{L} \Delta k\right)\end{array}$} & \multicolumn{2}{|c|}{$\begin{array}{c}w_{H}^{*}=\frac{2\left(c_{H}+y\right)\left(B-2 c_{L} b\right)}{\lambda B+2\left(c_{H}+y\right)\left(k_{L} \lambda+2 c_{L}\right)} \\
w_{L}^{*}=\frac{2 c_{L}\left[2 k_{L}\left(c_{H}+y\right)-A b\right]}{\lambda B+2\left(c_{H}+y\right)\left(k_{L} \lambda+2 c_{L}\right)} \\
A=\lambda \Delta k+2\left(c_{H}+y\right) \\
B=k_{L} \lambda \Delta k+2 c_{L} k_{H}\end{array}$} \\
\hline
\end{tabular}


Table 3: Equilibrium price and quantity values for fixed parameter values for four COOL scenarios.

\begin{tabular}{|c|c|c|c|c|c|}
\hline \multicolumn{2}{|c|}{ Parameter values: $k_{H}=1.5$} & \multicolumn{4}{|c|}{$k_{L}=c_{L}=1 \quad \alpha=0.5 \quad \eta=0.5 \quad b=0.02 \quad y=0.0025$} \\
\hline Sector & $\begin{array}{l}\text { Equilibrium } \\
\text { price and } \\
\text { quantity }\end{array}$ & No COOL & $\begin{array}{l}\text { Voluntary } \\
\text { COOL }\end{array}$ & $\begin{array}{l}\text { Partial } \\
\text { MCOOL }\end{array}$ & $\begin{array}{l}\text { Total } \\
\text { MCOOL }\end{array}$ \\
\hline \multirow[t]{3}{*}{ Retail } & $p_{H}, q_{H}$ & $\mathrm{~N} / \mathrm{A}$ & $0.787,0.364$ & $0.827,0.417$ & $0.885,0.247$ \\
\hline & $p_{L}, q_{L}$ & $\mathrm{~N} / \mathrm{A}$ & $\mathrm{N} / \mathrm{A}$ & $0.535,0.048$ & $0.509,0.244$ \\
\hline & $\bar{p}, q_{L}$ & $0.707,0.435$ & $0.627,0.134$ & $\mathrm{~N} / \mathrm{A}$ & $\mathrm{N} / \mathrm{A}$ \\
\hline \multirow[t]{3}{*}{ Foodservice } & $p_{H}, q_{H}$ & $\mathrm{~N} / \mathrm{A}$ & $\mathrm{N} / \mathrm{A}$ & $\mathrm{N} / \mathrm{A}$ & $0.885,0.247$ \\
\hline & $p_{L}, q_{L}$ & $\mathrm{~N} / \mathrm{A}$ & $\mathrm{N} / \mathrm{A}$ & $\mathrm{N} / \mathrm{A}$ & $0.509,0.244$ \\
\hline & $\bar{p}, q_{L}$ & $0.707,0.435$ & $0.627,0.498$ & $0.605,0.516$ & $\mathrm{~N} / \mathrm{A}$ \\
\hline
\end{tabular}

Note: N/A refers to not applicable

Table 4: Welfare magnitude comparisons for fixed parameter values for four COOL scenarios.

\begin{tabular}{|c|c|c|c|c|}
\hline \multicolumn{5}{|c|}{ Parameter values: $k_{H}=1.5 \quad k_{L}=c_{L}=1 \quad \alpha=0.5$} \\
\hline & No COOL & $\begin{array}{l}\text { Voluntary } \\
\text { COOL }\end{array}$ & $\begin{array}{l}\text { Partial } \\
\text { MCOOL }\end{array}$ & $\begin{array}{l}\text { Total } \\
\text { MCOOL }\end{array}$ \\
\hline Retailer Profit & 0.118 & 0.171 & 0.151 & 0.136 \\
\hline Foodservice Profit & 0.118 & 0.155 & 0.166 & 0.136 \\
\hline $\begin{array}{l}\text { Expected Consumer } \\
\text { Surplus }\end{array}$ & 0.236 & 0.327 & 0.318 & 0.272 \\
\hline $\begin{array}{l}\text { Real Consumer } \\
\text { Surplus }\end{array}$ & 0.066 & 0.214 & 0.222 & 0.272 \\
\hline $\begin{array}{l}\text { Domestic Producer } \\
\text { Surplus }\end{array}$ & $\mathrm{N} / \mathrm{A}$ & 0.075 & 0.098 & 0.138 \\
\hline Total Welfare* & 0.302 & 0.615 & 0.638 & 0.681 \\
\hline
\end{tabular}

*Total Welfare $=$ Real Consumer Surplus+Domestic Producer Surplus+Retail and Foodservice Profits 
Figure 1: Four market scenarios for COOL

\section{Scenario 1. No COOL}
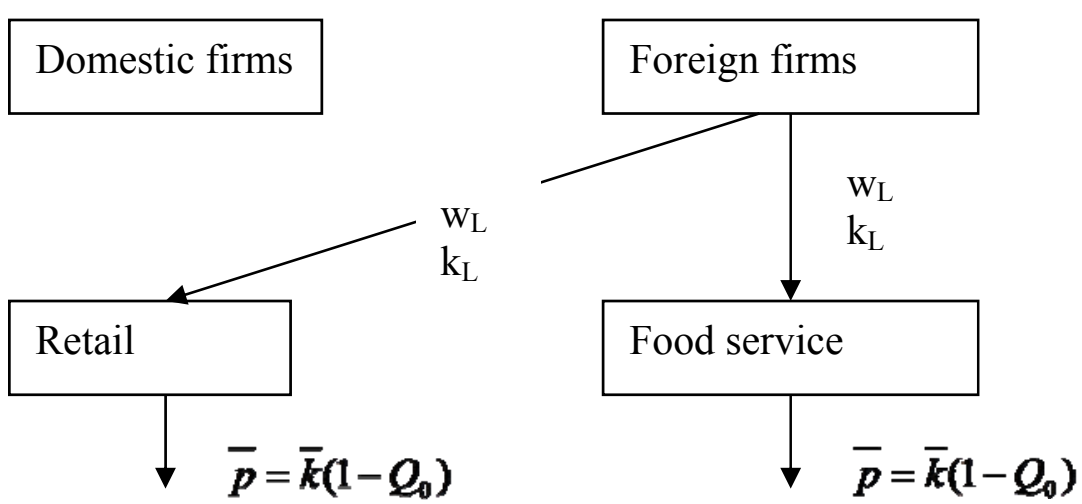

2. Voluntary COOL Labeling at Retail
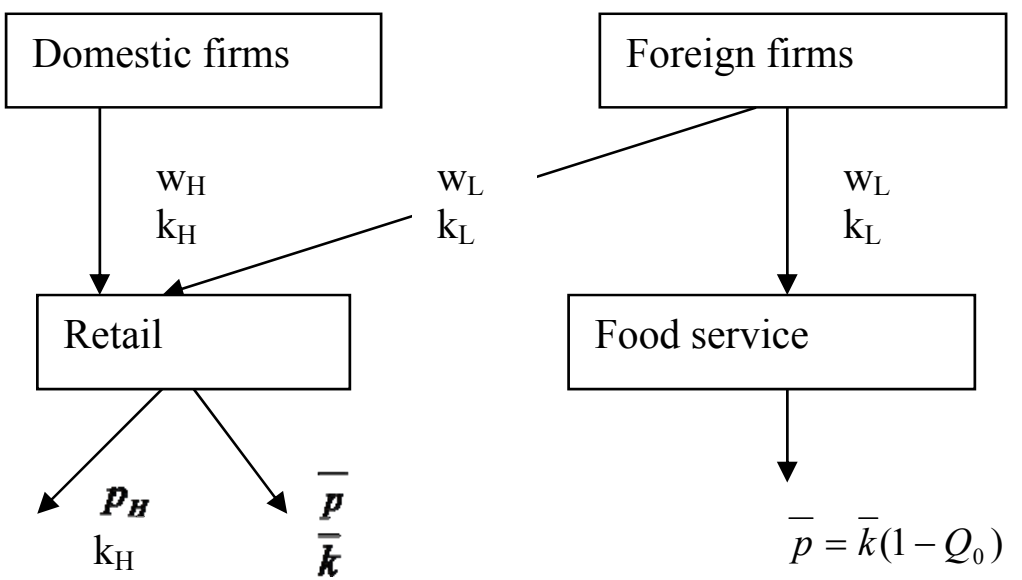

\section{Partial MCOOL Implementation at Retail}
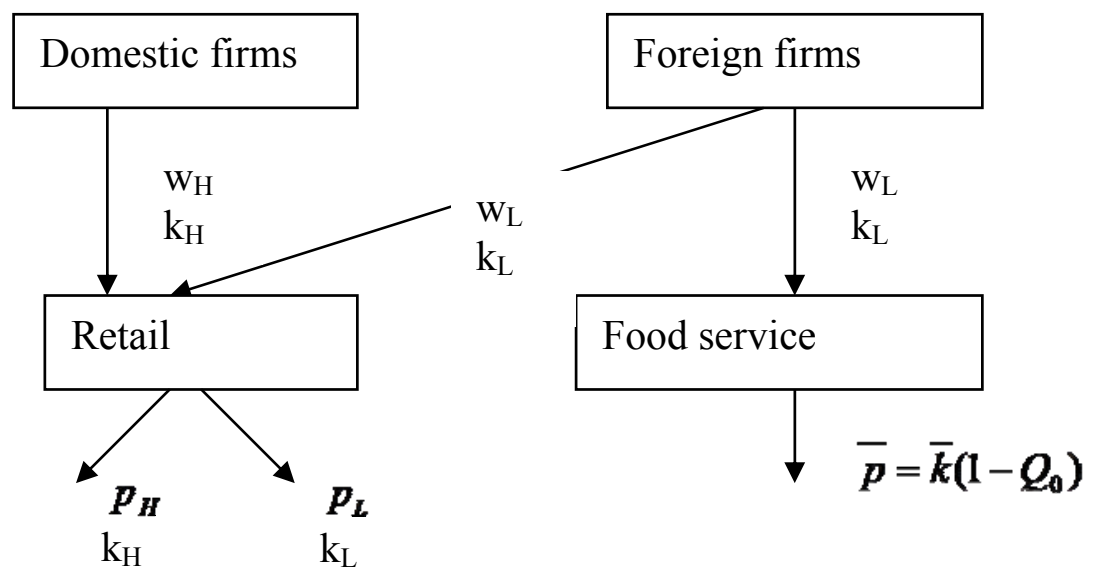

4. Total MCOOL Implementation at Retail \& Foodservice

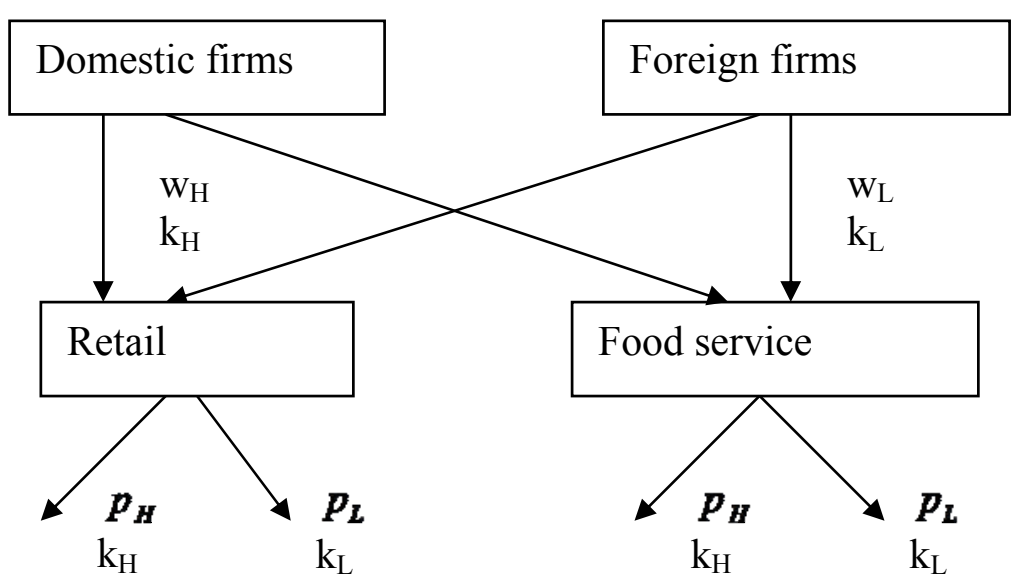


Figure 2: Effect of increasing quality differences between domestic and foreign product on retailer profit under four COOL scenarios $(\eta=0.5, \alpha=0.5)$

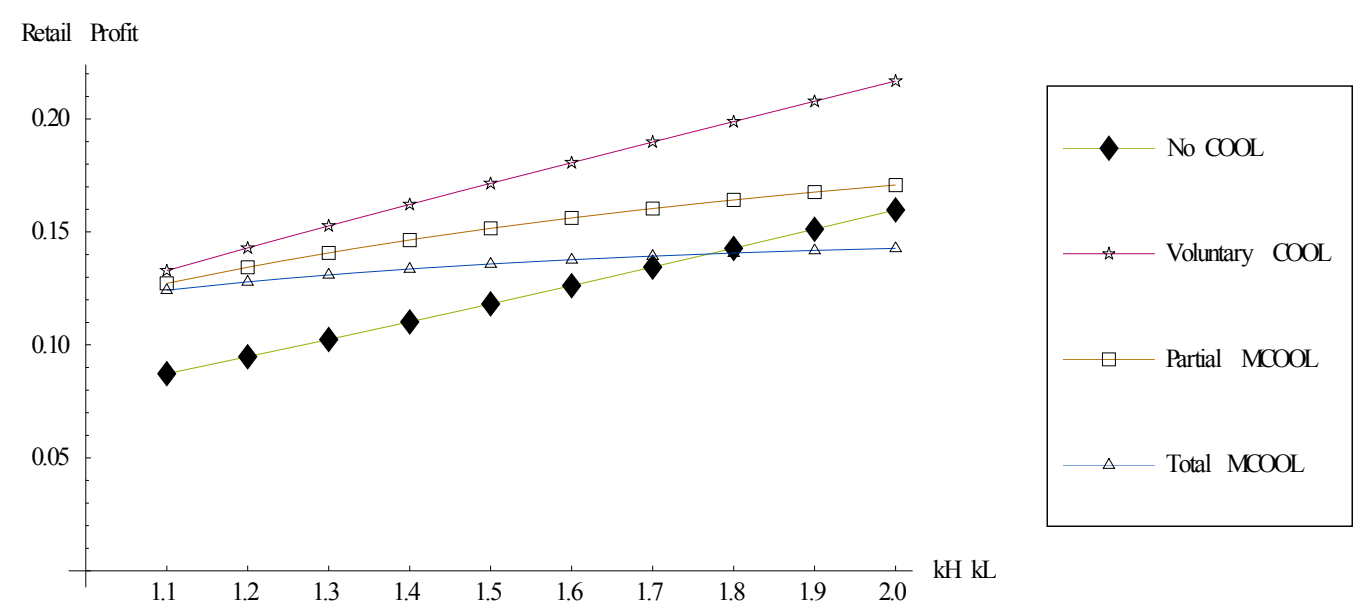

Figure 3: Effect of varying labeling costs on retailer profit under four COOL $\operatorname{scenarios}\left(k_{H}=1.1, \eta=0.5, \alpha=0.5\right)$

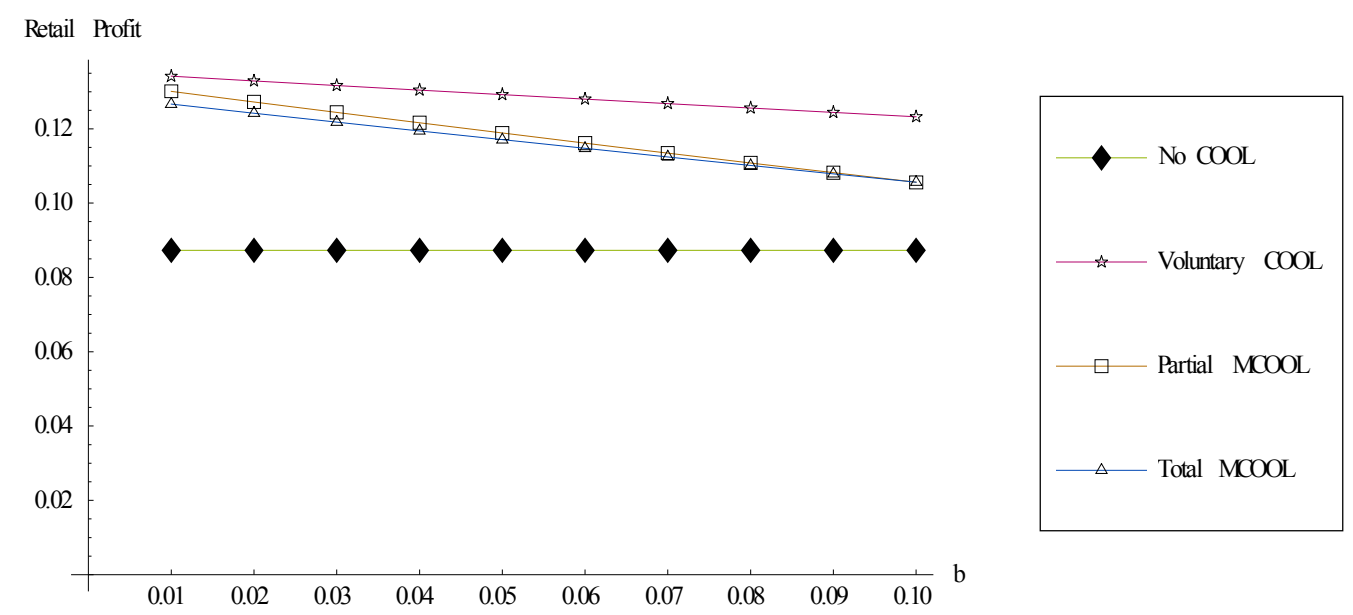


Figure 4: Diversion under Partial MCOOL

a. Voluntary COOL at Retail

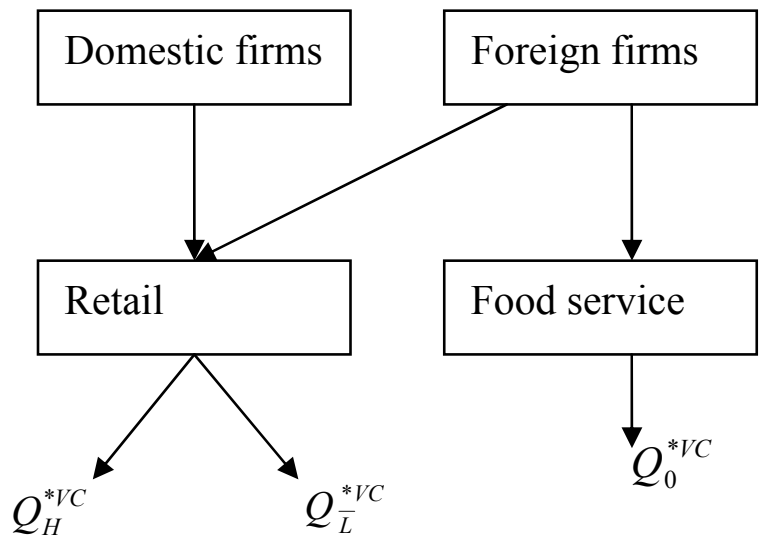

\section{b. Partial MCOOL at Retail}

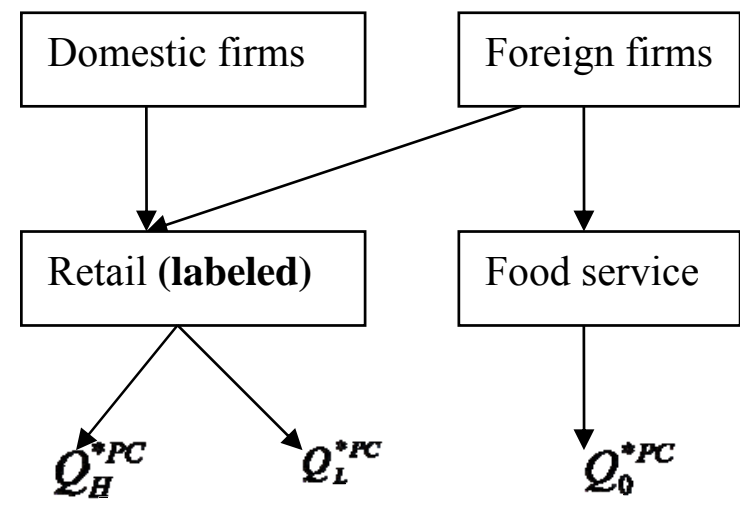

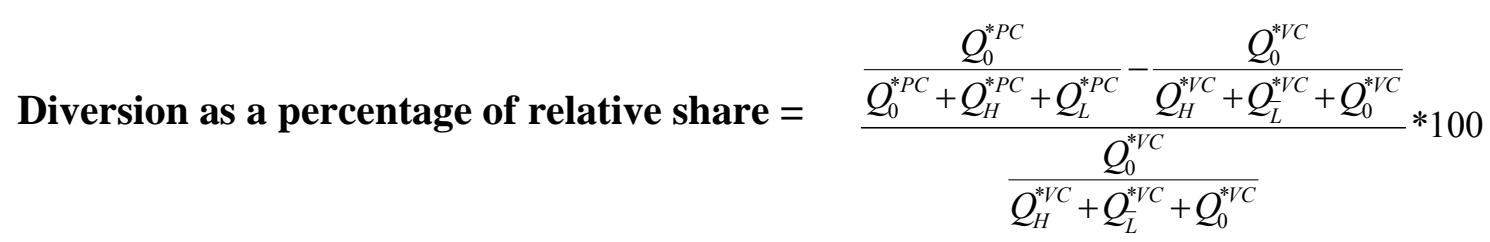


Figure 5: Effect of increasing perceived quality differences between domestic and foreign product on diversion percentage under partial MCOOL $(\eta=0.5, \alpha=0.5)$

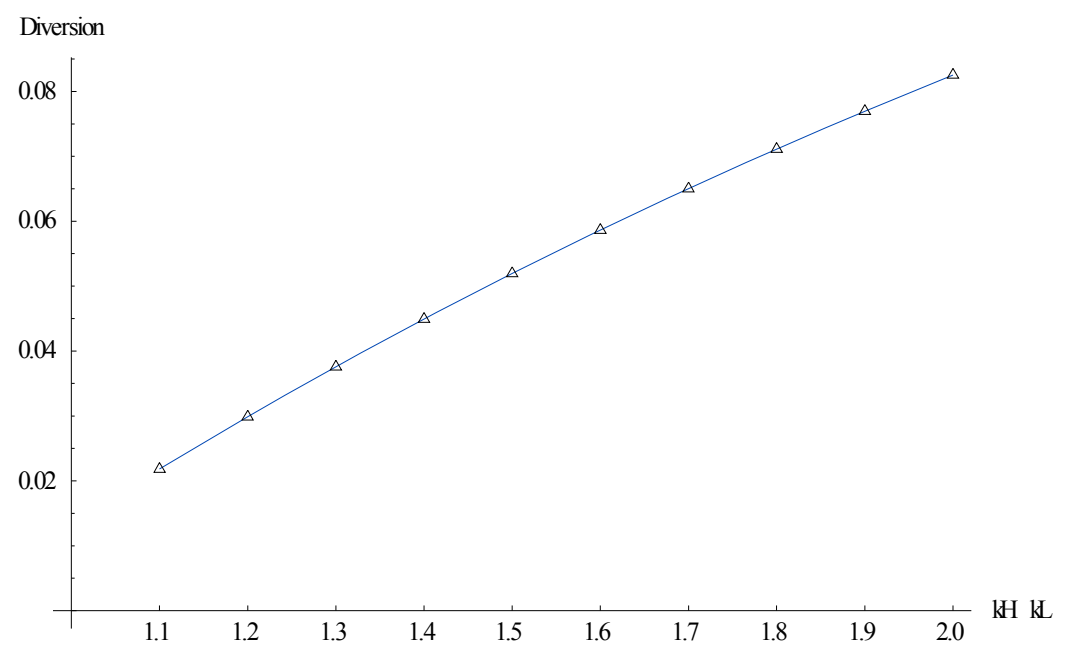


Figure 6a: Effect of increasing perceived quality differences between domestic and foreign product on foodservice profit when quality misperception is low $(\eta=0.5, \alpha=0.1)$

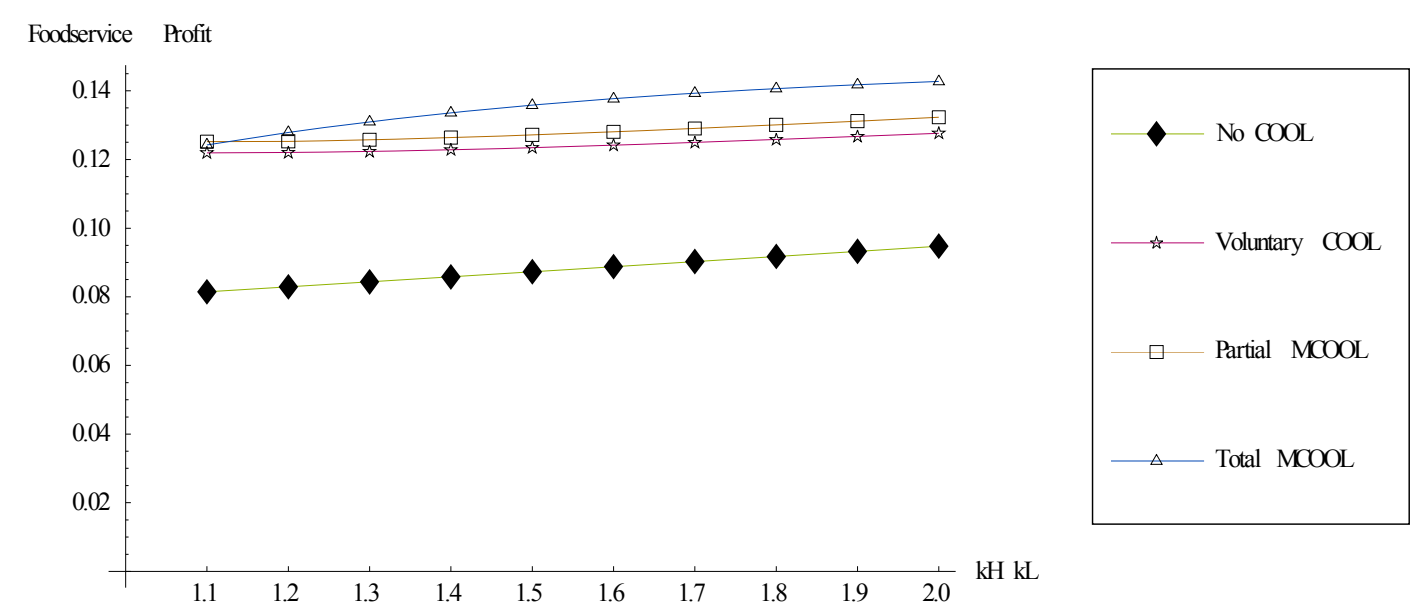

Figure 6b: Effect of increasing perceived quality differences between domestic and foreign product on foodservice profit when quality misperception is high $(\eta=0.5, \alpha=0.9)$

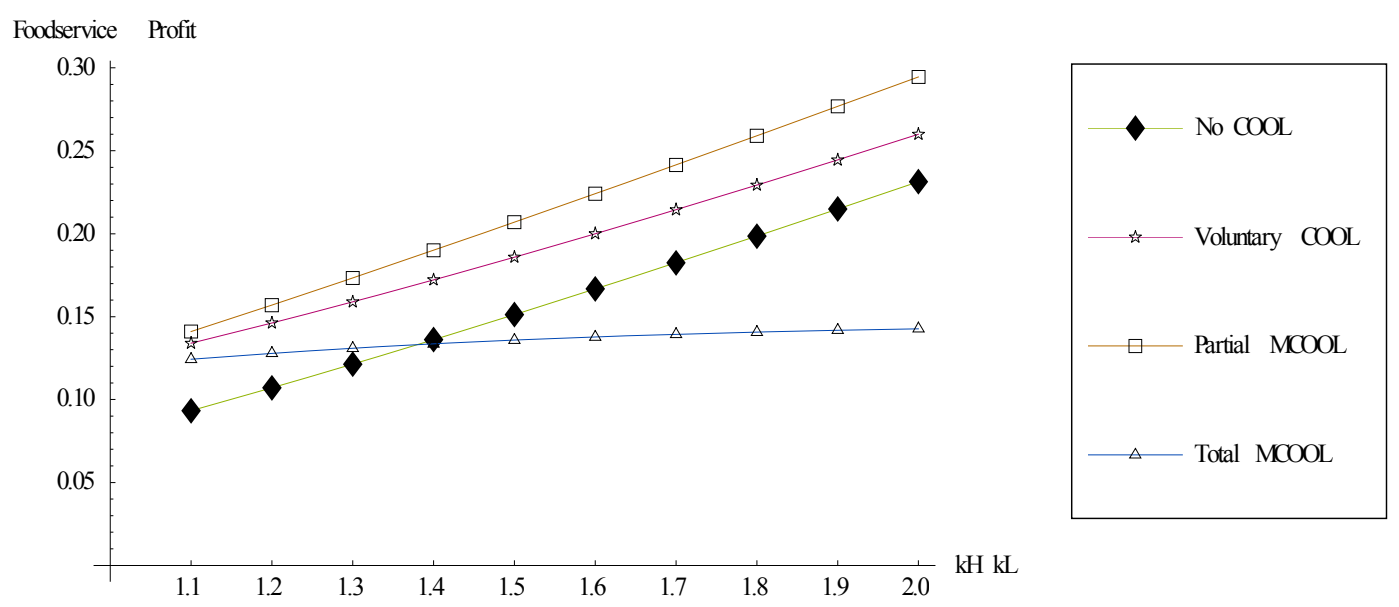


Figure 7a: Effect of increasing perceived quality differences between domestic and foreign product on Real consumer surplus when quality misperception is $\operatorname{low}(\eta=0.5, \alpha=0.1)$

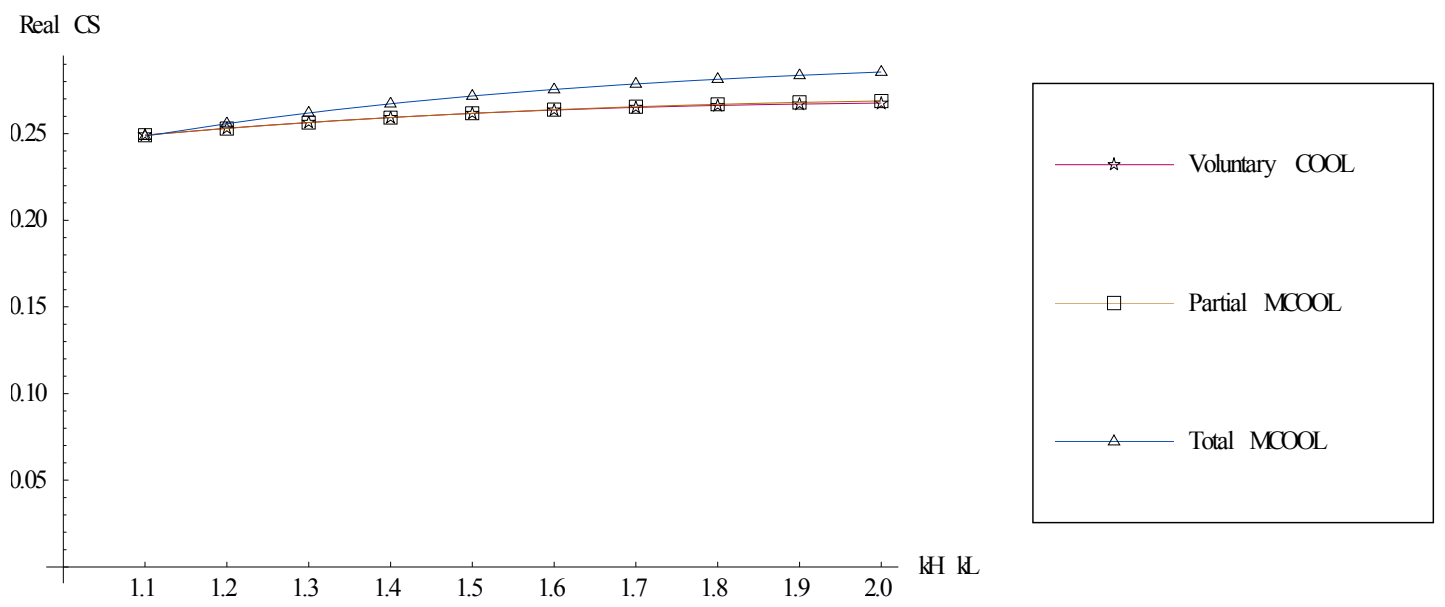

Figure 7b: Effect of increasing perceived quality differences between domestic and foreign product on Real consumer surplus when quality misperception is high ( $\eta=0.5, \alpha=0.9)$

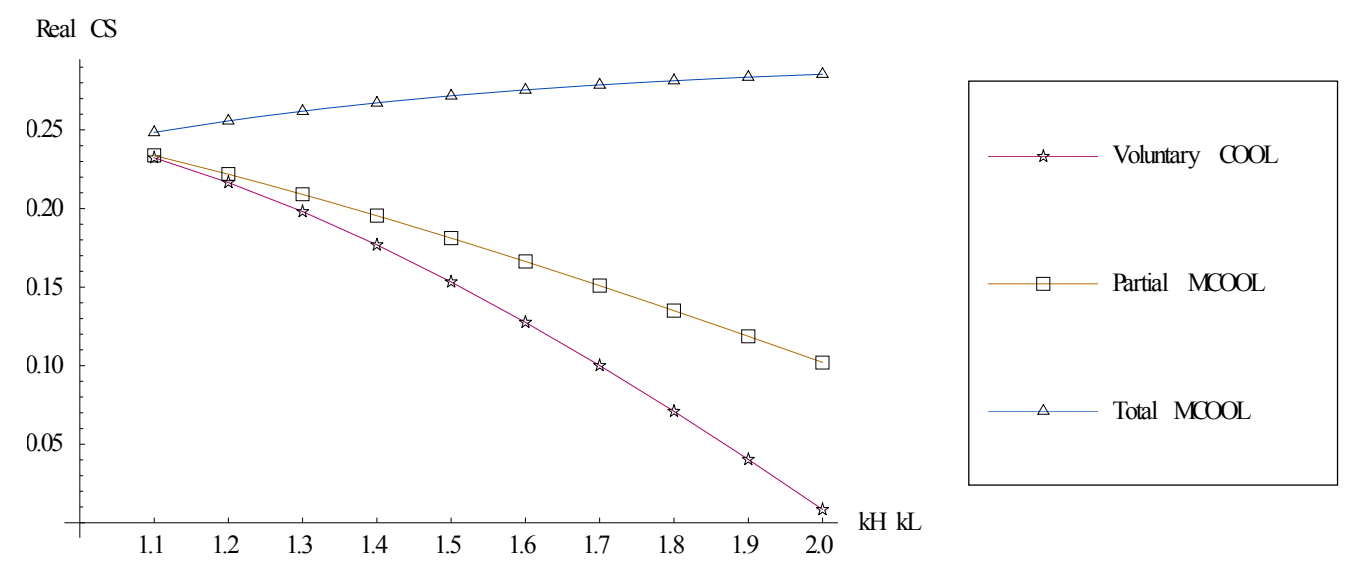


Figure 8a: Effect of increasing perceived quality differences between domestic and foreign product on domestic producer surplus when quality misperception is low $(\eta=0.5, \alpha=0.1)$
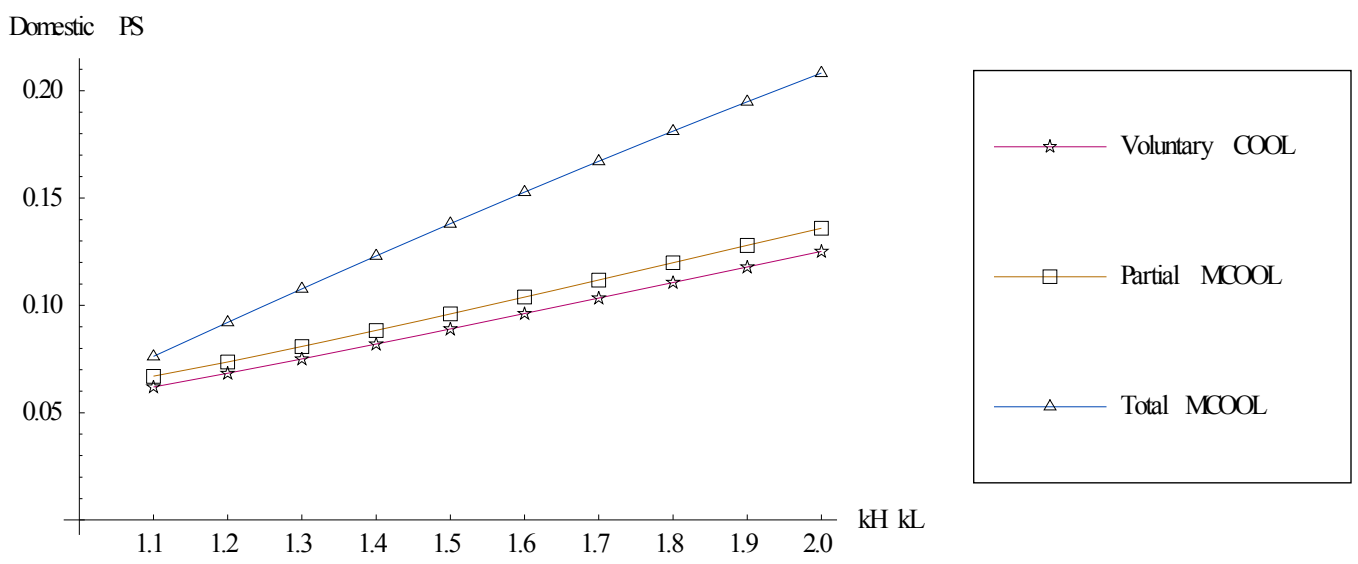

Figure 8b: Effect of increasing perceived quality differences between domestic and foreign product on domestic producer surplus when quality misperception is high $(\eta=0.5, \alpha=0.9)$
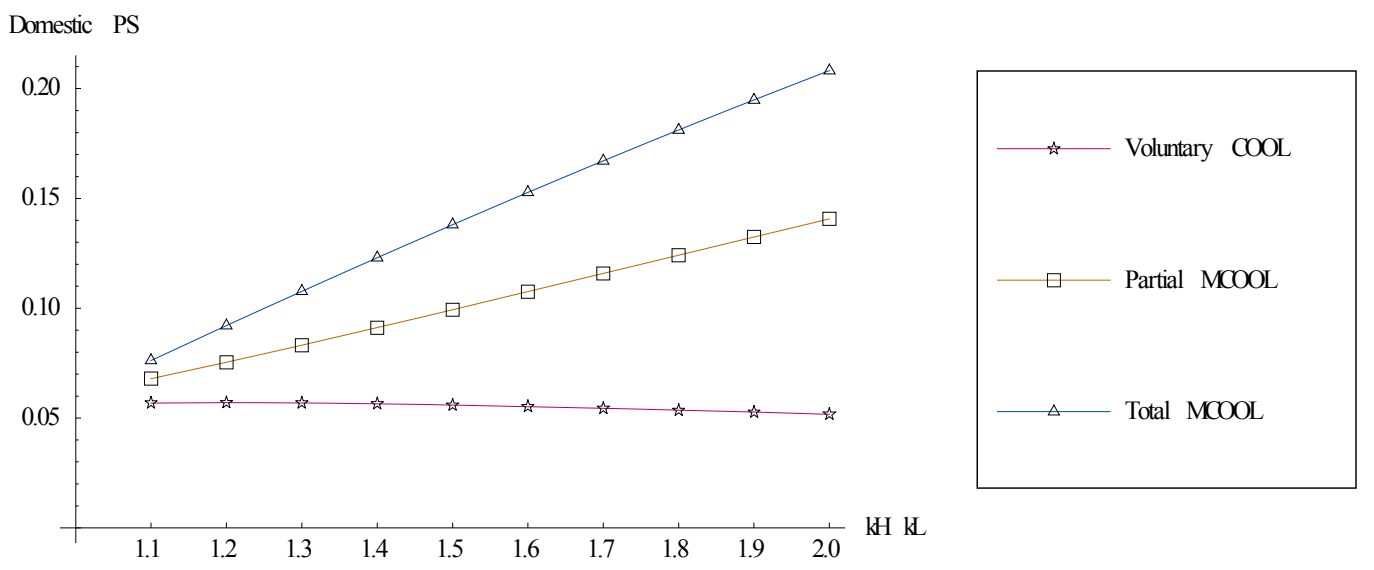
Figure 9a: Effect of increasing perceived quality differences between domestic and foreign product on total welfare when quality misperception is low $(\eta=0.5, \alpha=0.1)$

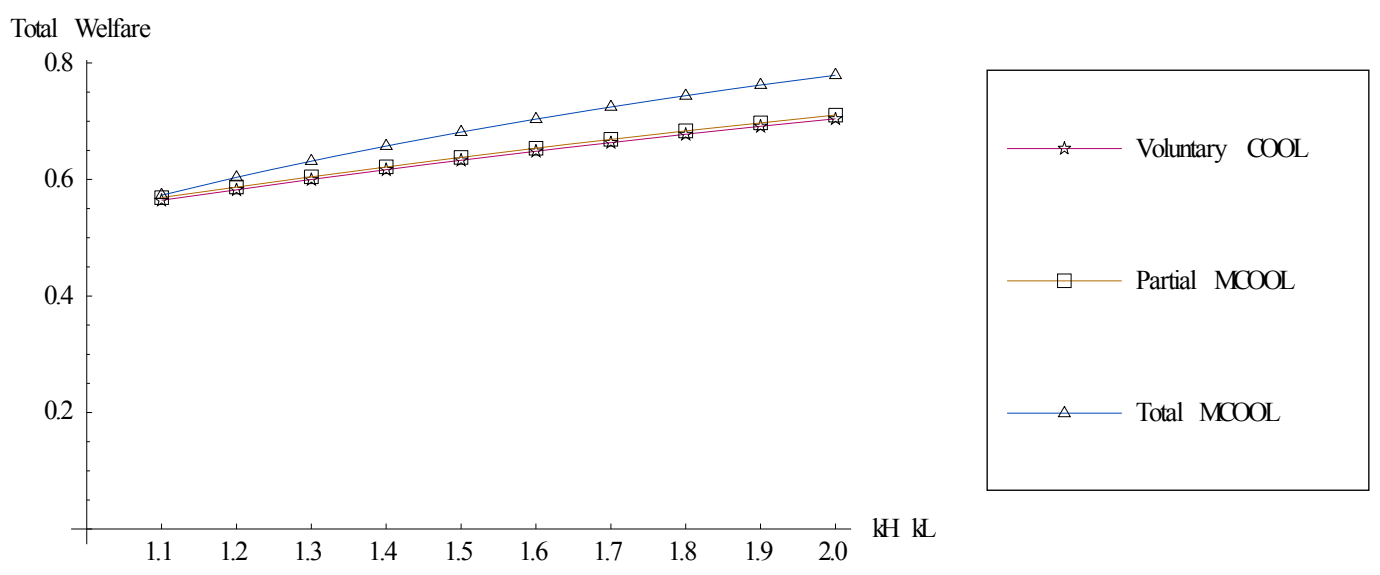

Figure 9b: Effect of increasing perceived quality differences between domestic and foreign product on total welfare when quality misperception is high $(\eta=0.5, \alpha=0.9)$

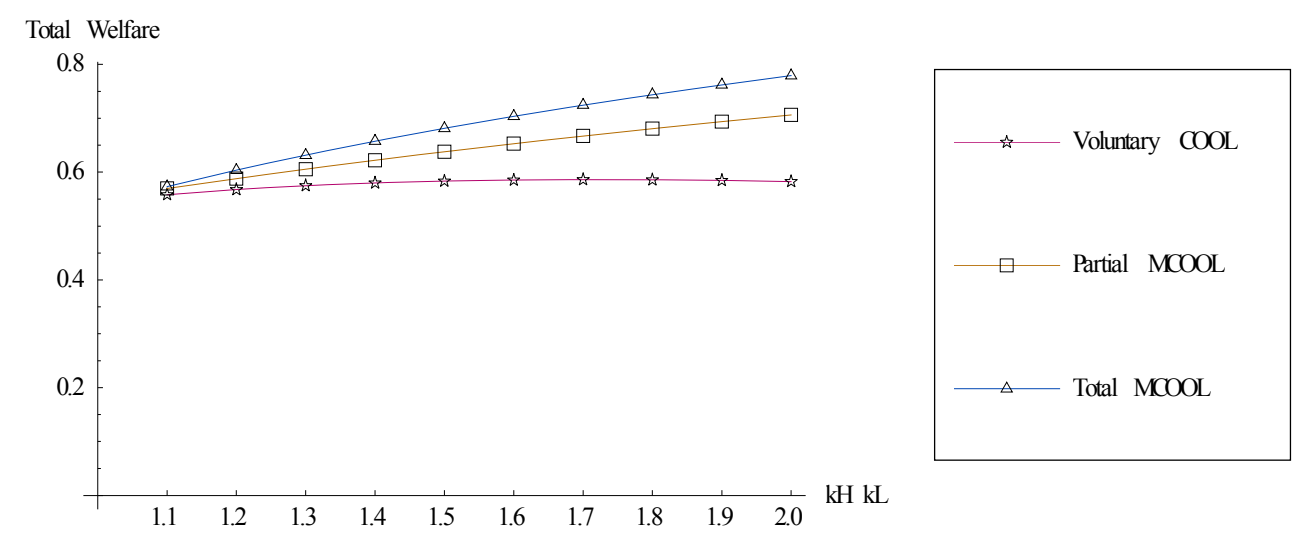


Figure 10a: Effect of increasing downstream market power on retailer profit when quality misperception is low $\left(\alpha=0.9, \boldsymbol{k}_{\boldsymbol{H}}=\mathbf{1 . 5}\right)$

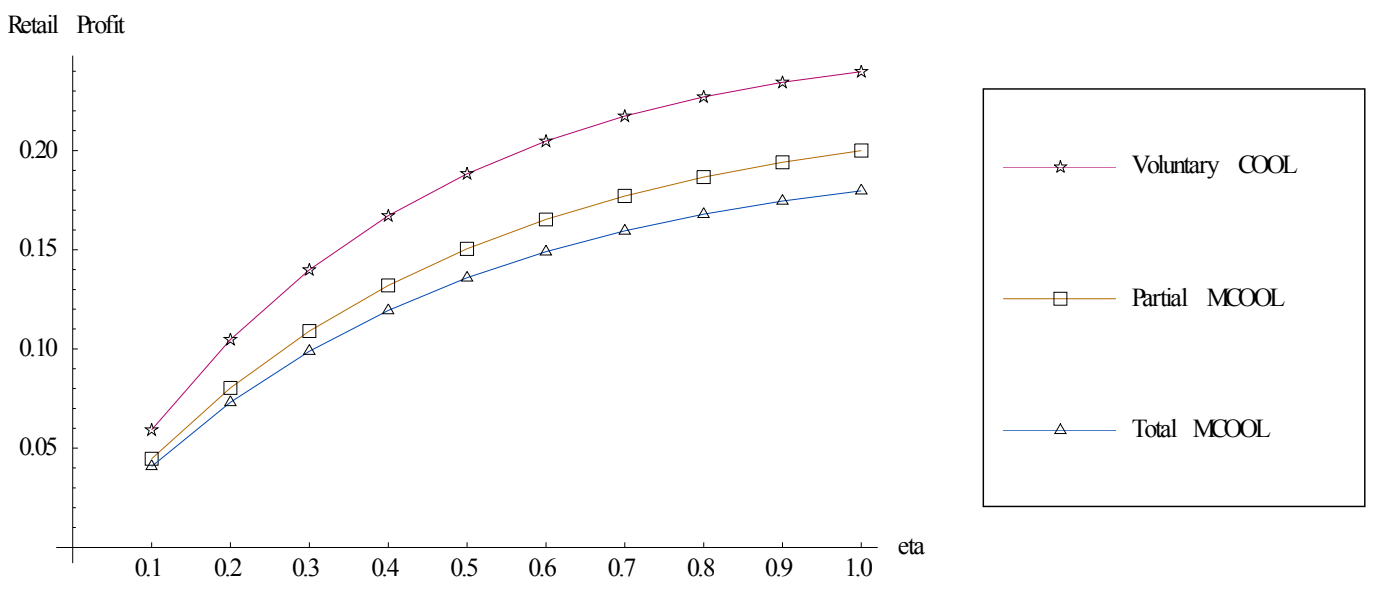

Figure 10b: Effect of increasing downstream market power on real consumer surplus when quality misperception is high $\left(\alpha=0.9, \boldsymbol{k}_{\boldsymbol{H}}=\mathbf{1 . 5}\right)$

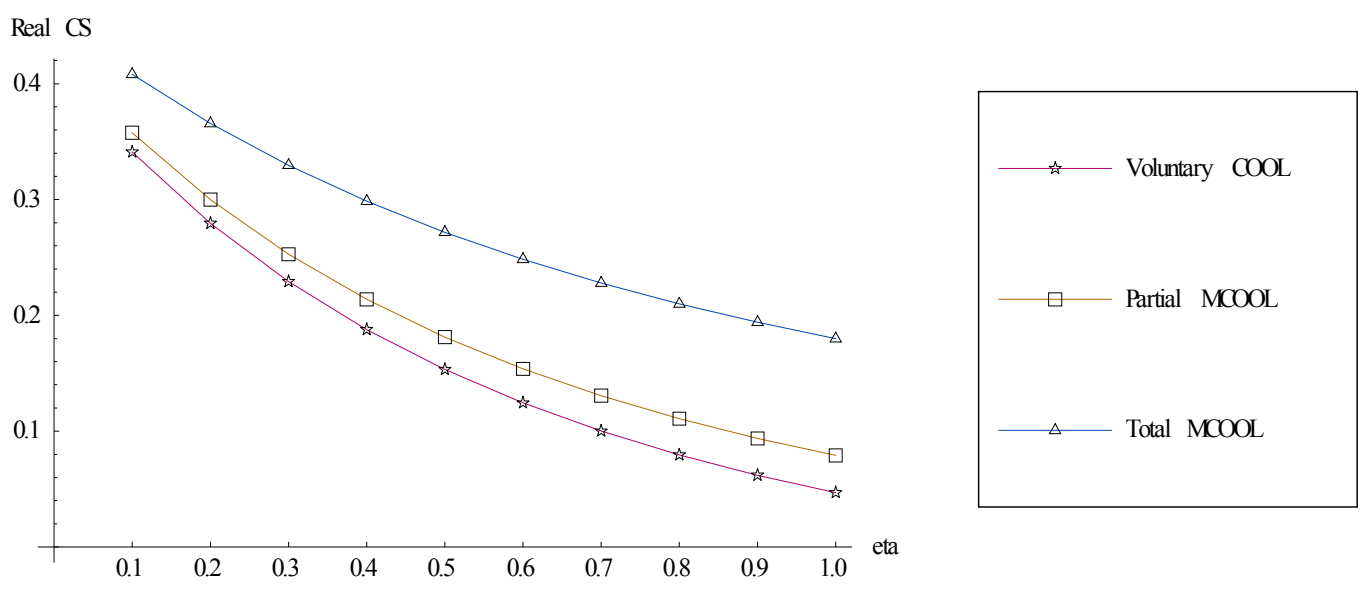

